\title{
Spatiotemporal dynamics of temperature and precipitation with reference to COVID-19 pandemic lockdown: perspective from Indian subcontinent
}

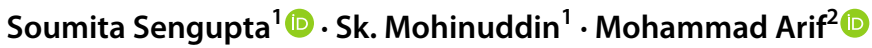

Received: 19 August 2020 / Accepted: 11 January 2021 / Published online: 29 January 2021

(c) The Author(s), under exclusive licence to Springer Nature B.V. part of Springer Nature 2021

\begin{abstract}
This study exclusively focuses on spatial and temporal change of temperature and precipitation before and after COVID-19 lockdown and also examines the extent of their variation and the spatial relationship between them. Our main objective is to analyze the spatiotemporal changes of two climatic variables in Indian subcontinent for the period of 20152020. Monthly precipitation and temperature data are collected from NOAA and NASA for January to May month across the four zones (northeast, northwest, central, and peninsular zone) of India. To conduct a zone-wise statistical analysis, we have adopted statistical process control (SPC) methods like exponentially weighted moving average (EWMA) control charts, individual charts (I- Chart) to detect the shift in temperature and precipitation over the study period and Pearson correlation coefficient applied to measure the spatial association between the two variables. The findings revealed that temperature parameter has experienced a lot of positive and negative trends in the span of 6 years and detected a weak to moderate negative correlation in many parts of the country in April 2020 after 2016. This study also identified a weak negative correlation mainly in NE zone in 2020 after 2017. This research provides vital scientific contribution to the effects of monthly temperature and precipitation before and after COVID-19 pandemic lockdown.
\end{abstract}

\section{Graphic abstract}

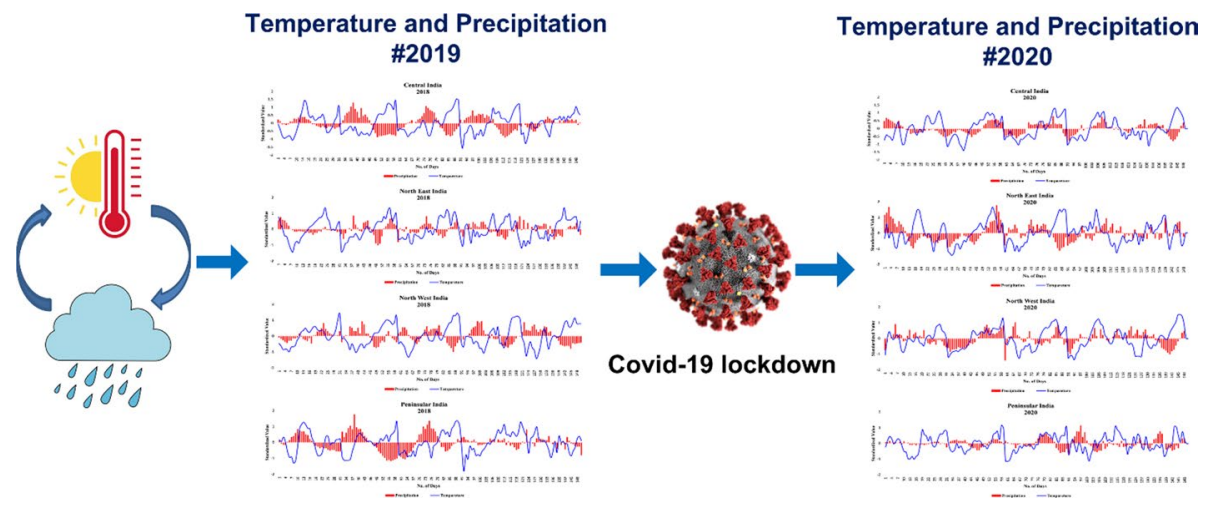

Extended author information available on the last page of the article 
Keywords Temperature $\cdot$ Precipitation $\cdot$ COVID-19 $\cdot$ Statistical process control $\cdot$ Pearson correlation coefficient

$\begin{array}{ll}\text { Abbreviations } & \\ \text { COVID-19 } & \text { Coronavirus disease 2019 } \\ \text { SARS-CoV } 2 & \text { Severe Acute Respiratory Syndrome Coro } \\ \text { WHO } & \text { World Health Organization } \\ \text { NW India } & \text { Northwest India } \\ \text { NE India } & \text { Northeast India } \\ \text { TMAX } & \text { Maximum temperature } \\ \text { TMIN } & \text { Minimum temperature } \\ \text { TMEAN } & \text { Mean temperature } \\ \text { CPC } & \text { Climate Prediction Center } \\ \text { GES DISC } & \text { Goddard Earth Sciences Data and Informatid } \\ & \\ \text { Methods } & \\ \text { SPC } & \text { Statistical Process Control } \\ \text { EWMA } & \text { Exponentially Weighted Moving Average } \\ \text { I-Chart } & \text { Individual Chart } \\ \text { CL } & \text { Centerline } \\ \text { UAL } & \text { Upper Action Lines } \\ \text { LAL } & \text { Lower Action Lines } \\ \text { UWL } & \text { Upper Warning Limit } \\ \text { LWL } & \text { Lower Warning Limit } \\ \text { SD } & \text { Standard Deviation } \\ \text { CV } & \text { Coefficient of Variation } \\ & \end{array}$

\section{Introduction}

The land of India is characterized by great diversity in its physical features, with a total area of 3,287,263 square kilometer, and is located in southeast Asia (Gadgil and Guha 1993). India is configured with a series of mountain ranges in the north and northeast, great Indian Desert in the northwest, Indo-Gangetic plain in center, dissected plateaus in the south and vast ocean in the southeast-southwest direction (Lal et al. 2018; Valdiya 2016). Based on the variations in its physiographic structure and relief, India is called a 'subcontinent'. Climate is a summary of mean weather conditions over a time period, usually based on 30 years of temperature, precipitation, and other climatic phenomena (Stephenson et al. 2008). The climate in India has many regional variations expressed in the pattern of different climatic factors. Temperature and precipitation are two significant components that are generally considered to be natural influences of climate (Groisman et al. 2005). Temperature is better predicted over the other due to its physical characteristics and more comprehensive historical data of all the climate factors (Allen and Ingram 2002; Trenberth and Shea 2005). Given that temperature and rainfall are critical weather variables, precise temperature and rainfall calculations are important for meteorology (Berg et al. 2009). The physical rationalization behind the precipitation-temperature relationship is that rainfall can affect soil moisture, which will also affect surface temperature (Huang and van den Dool 1993). The association 
between the rainfall and temperature is usually assumed to change between months. For example, Rajeevan et al. (1998) looked at the temporal relationship between terrestrial surface temperature and rainfall and found that temperature and rainfall correlated positively during January and May but correlated negatively during July. Using annual data, Huang et al. (2009) also documented a negative correlation between precipitation and temperature in China's Yellow river basin. The further analysis investigated a detailed picture of the monthly rainfall data at meteorological stations, well distributed across India over 114 years (1871-1984) (Kumar et al. 1992). Some researchers only examined 4-month and two-season maximum and minimum temperatures of two seasons and 4 months (January, April, May, and December). In the report, the 2 months of April-May were regarded as the summer season and another 2 months of December-January as the winter season (Huq et al. 2004). Exploring the variability and shifts in temperature and rainfall patterns across various spatial horizons was therefore core aspects of climate and meteorology research (Chatterjee et al. 2016; Rao et al. 2014; Sonali and Kumar 2013). There have been extensive studies on both seasonal and annual time frames on precipitation and temperature measurement (Utsumi et al. 2011; Dugam and Kakade 2003; Deshpande et al. 2012; Pattanaik and Rajeevan 2007; Kumar et al. 1997; Joshi and Rajeevan 2006).

Generally, researchers have used different statistical methods (Sonali and Kumar 2013) like regression test, Kendal rank correlation test, statistical process control method, Sen's slope estimation, and exponentially weighted moving average method (Haan 1977; Bevan and Kendall 1971; Vucijak et al. 2012; Sen 1968; Schmid and Schöne 1977). In the present paper, we have applied the nonparametric test like statistical process control (SPC) method to analyze temperature and precipitation across India. This nonparametric method is widely used in detecting the smaller shift in the climatic change (Naveed et al. 2018; Justin et al. 2012; Eyvazian et al. 2008). By exploring the literature, we found that no study as of yet utilizes the SPC chart for comparing and monitoring climatic variables. So the change detection analysis in temperature and precipitation data series was carried out by exponentially weighted moving average (EWMA) control chart and I-Chart, respectively. This research applies EWMA control charts to detect the variation of temperature in order to detect shifts in the climate of India. A I-Chart is used for the detection of small to moderate shifts to the zone-wise minimum and maximum monthly average rainfall (Bakker et al. 2008). To study the interdependence between rainfall and temperature, the correlation coefficient was found to be essential. Researchers have explored a direct association between temperature and precipitation over the Indian subcontinent (Radhakrishnan et al. 2017). In this study, an attempt is made to illustrate the relationship between precipitation and temperature by examining the correlation between these two climatic elements. The study deals with temperature and rainfall over four different metrological subdivisions of India defined by northwest India, northeast India, central India, and peninsular India. The novelty of the present study is that the application of EWMA and I-Chart is very much effective for different meteorological divisions as this model analyzes trend details in annual and seasonal precipitation and temperature with high precision. Statistical process control (SPC)-based explanation has gained popularity around the globe as it produces reliable results. It is expected that this research would also be highly useful as it was performed at a micro-level on the whole Indian subcontinent.

The global pandemic due to the novel coronavirus SARS-CoV-2 represents a significant and urgent threat to global health. The COVID-19 pandemic is proving to be one of the greatest challenges that the modern world has ever faced. The recently emerged novel 
coronavirus was first discovered in Wuhan city of China (WHO 2020a; Zu et al. 2020). The world outside of China has awakened to the severity of this year's novel coronavirus outbreak in March (Ji et al. 2020). In India, the first case of COVID-19 was detected on 30 January 2020 in the state of Kerala (WHO 2020a). It has spread quickly to a number of countries and was declared a pandemic by the World Health Organization on 11 March 2020 (WHO 2020b) and as of March 25, the residence of more than 1.38 billion people; India's prime minister placed a complete lock down (Census of India 2011; The New York Times, 2020). To abate the spread of the novel coronavirus-2 (SARS-CoV-2), different countries across the globe responded to include containment measures like lockdowns and quarantines refrain from going out the residing place (Gautam and Hens 2020). On 24 March 2020, the Government of India has implemented a nationwide lockdown and enacted social distancing norms for 21 days (Phase-I), from 25th March-14th April 2020, further extending this in Phase-II (15 April-3 May) and then to Phase-III (May 3-May 17) and thereafter, with significant exemptions for transport industry and commercial establishments, the lockdown was further extended until 31 May (Phase-IV). This situation of lockdown has created a golden opportunity to assess climatic components at very local to regional scales (Arif and Sengupta 2020; Bherwani et al. 2020; Anjum 2020). Studies reported that the climatic condition in India has improved in terms of either water or air pollution mitigation due to the lockdown (Arora et al. 2020; Somani et al. 2020; Roy 2020). It has stated that temperature and precipitation have drastically changed during the period of lockdown. Based on the assumption that various climatic conditions carry out an important role in the COVID-19 pandemic lockdown, it is essential to identify relation between different climatic factors such as precipitation and temperature. This research article carries out a statistical analysis of 6 years' (2015-2020) temperature and rainfall data for the different meteorological divisions. The objectives of the present study are: (1) to analyze the variability in the monthly rainfall for four meteorological divisions, (2) to explore the change of minimum, maximum, and mean monthly temperature variability analysis, (3) to assess any significant correlation between precipitation and temperature in the months and years of the four zones, and (4) lastly to investigate any changing pattern of the climate variables (rainfall and temperature) due to one of the COVID-19 containment measures lockdown and to examine the extent of variation.

\section{Methodology}

\subsection{Study area}

The study has been conducted over Indian mainland (Fig. 1), which is located within $08^{\circ} 04^{\prime} \mathrm{N}$ to $37^{\circ} 06^{\prime} \mathrm{N}$ latitude and $68^{\circ} 07^{\prime} \mathrm{E}$ to $97^{\circ} 25^{\prime} \mathrm{E}$ longitude. The elevations of the country varied from 300 to $600 \mathrm{~m}$ above the mean sea level. The climatic conditions of the India are characterized by different climatic zones, such as hot-dry, warm-humid, temperate, and cold (Ali et al. 1993). Depending on the pattern, distribution, occurrence of rainfall, temperature and the mean long-term rainfall, and its variability, entire India has been categorized into four homogeneous climate regions, such as northwest India (NW India), northeast India (NE India), central India and peninsular India (Guhathakurta and Rajeevan 2008; Guhathakurta et al. 2015; Zheng et al. 2016, www.imd.gov.in). India experiences 


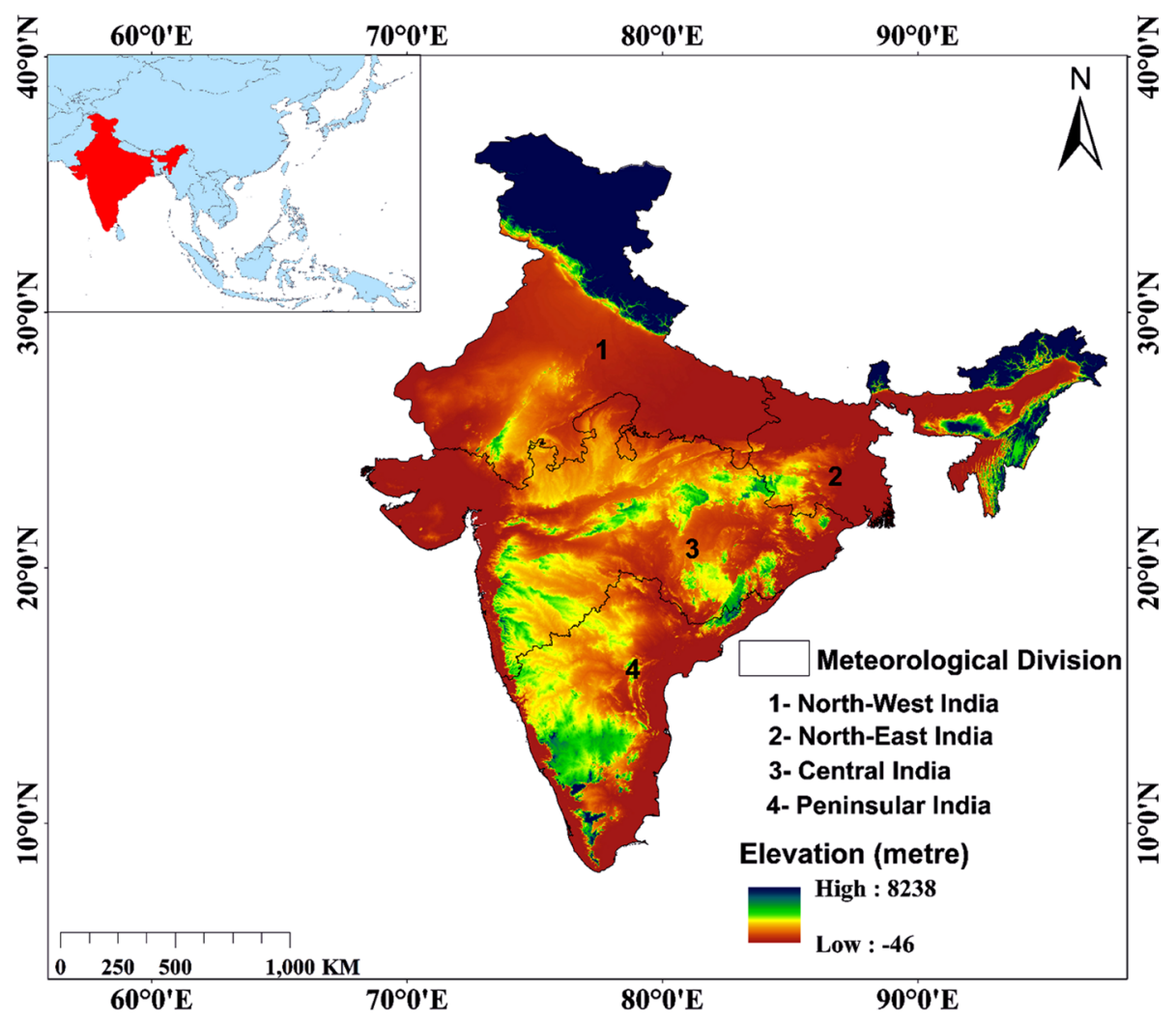

Fig. 1 The study area with meteorological divisions, viz. northwest, northeast, central and peninsular zone

almost all kinds of climate because of its physiographical divisions (Martinez-Austria et al. 2016). Winter (January-February), summer (March-May), monsoon (June-September), and post-monsoon (October-December) are the major seasons prevailing over Indian subcontinent (Laskar et al. 2016). During the month of monsoon, India receives $117 \mathrm{~cm}$ of rainfall which is about 80 percent of total rainfall (Sahai et al. 2003). The average rainfall (\% standard deviation) is 1324.6 (11\%), 618.7(19\%), 976.4 (14\%), and 730.5 (15\%) $\mathrm{mm}$ for NE, NW, central, and peninsular India, respectively (Das et al. 2017). In this analysis, daily temperature and rainfall datasets have been extracted from the Climate Prediction Center (CPC) Global Daily Temperature Time Series (https://psl.noaa.gov/data/gridded/) and Goddard Earth Sciences Data and Information Services Center (GES DISC) (https:// disc.gsfc.nasa.gov/), respectively. Data were obtained from January to May for a period of 6 years (2015-2020). The Global gridded high-resolution station data for daily temperature are available from 1979 to the present in a $0.50 \times 0.50$ grid. From 2000 to the present, the Global average precipitation datasets are available in a grid of $0.10 \times 0.10$. The datasets are downloaded in NetCDF (.nc) format, and further, spatial sub-setting has been performed to limit our study for the Indian subcontinent. 


\subsection{Data analysis}

The analysis was started by evaluating the monthly arithmetic mean temperature and rainfall of the gridded spatial data of the whole study area. TMean, TMax, and TMin were observed for the monthly data series. Zonal statistics were performed to extract the zone-wise maximum, minimum, and mean value for these two climate variables while using definite functions, datasets and shape files.

\subsubsection{Analysis precipitation data}

A zone-wise monthly variation of SPC-I chart of the rainfall data was used in this study to spot the changes in variability. I-Chart is commonly adopted when the data are unavailable on frequent basis (SPC for Excel 2013). To prepare the I-Chart, the centerline (CL) has been placed at the mean of the preceding performances, while the upper and lower action lines (UAL and LAL) have been placed at three standard deviations (SD) from the centerline. The upper and lower warning lines (UWL and LWL) have been placed at two standard deviations from the centerline (CL) (Oakland 2007). For better understanding, the control limits for preparing the I-Chart are given below:

$$
\text { Standard deviation }(\sigma)=\sqrt{\frac{\sum\left(x_{i}-\mu\right)^{2}}{N}}
$$

where $x_{i}=$ individual sample value, $\mu=$ sample mean, $N=$ size of the sample.

Upper action limit $(\mathrm{UAL})=$ Average $+3 *$ standard deviation

Upper warning limit $(\mathrm{UWL})=$ Average $+2 *$ standard deviation

$$
\text { Center line }=\text { Average }
$$

Lower warning limit $(\mathrm{LWL})=$ Average $-2 *$ standard deviation

Lower action limit $(\mathrm{LAL})=$ Average $-3 *$ standard deviation

While plotting the distinct results on the I-Chart, the rules for "out of control" situations are as follows (Vucijak et al. 2012):

(i) Any point falling outside the $3 \mathrm{SD}$ limits;

(ii) Two out of three successive points are outside the 2 SD limits;

(iii) Eight points in a run on one side of the mean.

\subsubsection{Analysis temperature data}

For observing and detecting the shifts in zone-wise temperature data, EWMA control charts to the mean monthly temperature were performed with the raw temperature data. EWMA can be used for continuous data from the entire process, detecting small shifts, estimate the mean, size of the subgroup sample $>1$ (Six sigma study guide 2015). EWMA calculates a weighted mean of the sequence by applying weights that decrease geometrically with the time of the observations (Perry 2011). In general, EWMA statistics $E W M A_{t}$ is defined by: 


$$
\mathrm{EWMA}_{t}=Z_{t}=\lambda x_{t}+(1-\lambda)_{z_{t-1}} \text { for } t=1,2,3, \ldots n
$$

where $0<\lambda<1$ is a weighted constant. The value $x_{t}$ refers to the mean temperature observation at time $t$ and $n=$ number of observations to be monitored including EWMA $_{0}$ (Croarkin et al. 2006). Significant increment and decrement occur at time $t$ when $z_{t}>\mathrm{UCL}$ and $z_{t}<$ LCL. For better understanding, the center line, upper control limit (UCL), and lower control limit (LCL) used to prepare the EWMA charts are given below:

$$
\begin{gathered}
\text { Centerline }=\mu 0 \\
\mathrm{UCL}=\mu 0+L \sigma \sqrt{\lambda /(2-\lambda)\left[1-(1-\lambda)^{2 t}\right.} \\
\mathrm{LCL}=\mu 0-L \sigma \sqrt{\lambda /(2-\lambda)\left[1-(1-\lambda)^{2 t}\right.}
\end{gathered}
$$

$L$ refers to the width of the control limits. It is recommended to use $\lambda=2$ and $L=3$ (Justin et al. 2012).

\subsubsection{Association between temperature and precipitation using Pearson correlation coefficient}

The correlation coefficient is one of the simplest methods to calculate the relationship of rainfall and temperature data. To measure the monotonic association between the two climate variables, the Pearson correlation coefficient was performed. A correlation coefficient can be defined as a numerical measure of a statistical relationship between two variables (Schober et al. 2018). One of the most significant features determines the strength or weakness of the monotonic association between variables through positive or negative correlation which ranges between -1.00 to +1.00 (Table 1). Therefore, the normalization of the data is important. The data normalization and statistical modeling work are carried out in $R$ statistical software. After normalization of all data sets, a correlation study was carried out using the 'Pearson product-moment correlation coefficient' to measure the strength and direction of association that exists between two climate variables. One of the main mathematical properties of the Pearson product-moment correlation coefficient is that it is invariant to position and scale shifts. The Pearson's coefficient $r$ was obtained using the following formula:

$$
r=\frac{n\left(\sum x y\right)-\left(\sum x\right)\left(\sum y\right)}{\sqrt{\left[n \sum x^{2}-\left(\sum x\right)^{2}\right]\left[n \sum y^{2}-\left(\sum y\right)^{2}\right]}}
$$

Table 1 Interpretation of the correlation coefficients

\begin{tabular}{ll}
\hline Correlation coefficient & Interpretation \\
\hline 0 and 0.3 & Weak positive linear relationship \\
0.3 and 0.7 & Moderate positive linear relationship \\
0.7 and 1.0 & Strong positive linear relationship \\
0 and -0.3 & Weak negative linear relationship \\
-0.3 and -0.7 & Moderate negative linear relationship \\
-0.7 and -1.0 & Strong negative linear relationship \\
\hline
\end{tabular}


where $n=$ number of pairs of score, $\sum x=$ sum of $x$ scores, $\sum y=$ sum of $y$ scores, $\sum x y=$ sum of the products of paired scores,

$\sum x^{2}=$ sum of squared $x$ scores, $\sum y^{2}=$ sum of squared $y$ scores.

The guidelines for interpreting the correlation coefficient (Ratner 2009) are given in Table 1.

In this study, we analyzed for maximum, minimum, mean, temperature, and rainfall data by nonparametric exponentially weighted moving average (EWMA) control chart and I-Chart and examined the spatial association and qualitative correlation between these two climatic variables using the R statistical software (version 4.0.0) (R Core Team 2020). The digital thematic maps representation have been prepared on ArcGIS platform (version 10.2.1) (ESRI 2017). Flowchart in Fig. 2 clearly depicts systematic methodological designs with sequential steps.

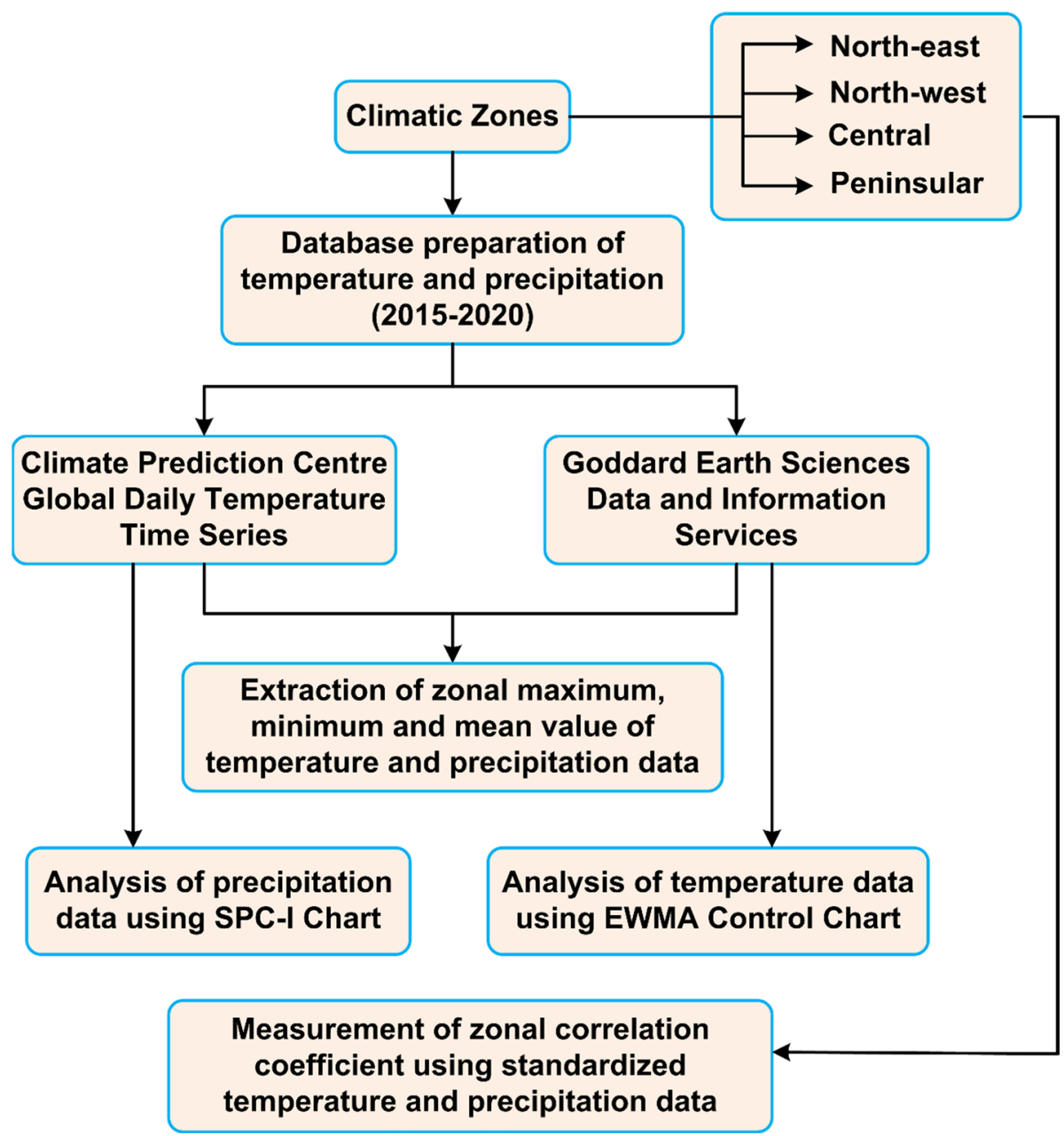

Fig. 2 Flowchart of the methodological framework 


\section{Results}

\subsection{Descriptive statistics}

We have calculated zonal descriptive statistics of precipitation and temperature from 2015 to 2020 for each of the four meteorological subdivisions of India (see Tables 2, 3, 4, 5, 6, 7, 8, 9, 10, 11, 12 and 13), (Figs. 3a-b and 4a-b). In such a case, the zonal maximum monthly average rainfall for the NE zone was observed to be $8.37 \mathrm{~mm}$ for April 2017, while the minimum value was found to be $0.23 \mathrm{~mm}$ for January 2018. The maximum standard deviation of rainfall was found to be $17.10 \mathrm{~mm}$ in 2016 , whereas the minimum value was $0.86 \mathrm{~mm}$ in 2018. The maximum and minimum value of the coefficient of variation of rainfall was found to be 380.24 in 2017 and 150.24 in 2020, respectively (Table 7). The NW zone was observed to receive less rainfall than the NE zone with a zonal maximum monthly average rainfall of $4.19 \mathrm{~mm}$ for March 2015 and a minimum of $0.32 \mathrm{~mm}$ for January 2018. The maximum standard deviation of rainfall for this zone was found to be $8.77 \mathrm{~mm}$ in 2017 , whereas the minimum value was $1.42 \mathrm{~mm}$ in 2018 . The maximum and minimum value of the coefficient of variation of rainfall was found to be 444.65 in 2018 and 140.00 in 2019, respectively (Table 6). The central zone was identified with a zonal maximum monthly average rainfall of $3.26 \mathrm{~mm}$ for March 2020 and a minimum of $0.01 \mathrm{~mm}$ for January 2018. The maximum standard deviation of rainfall was found to be $7.75 \mathrm{~mm}$ in 2020 , whereas the minimum value was $0.09 \mathrm{~mm}$ in 2018 . The maximum and minimum value of the coefficient of variation of rainfall was found to be 902.39 in 2018 and 190.74 in 2015, respectively (Tables 5 and 6) (Fig. 3b and a). The peninsular zone was observed to have a zonal maximum and minimum monthly average rainfall of $4.42 \mathrm{~mm}$ for May 2016 and $0.03 \mathrm{~mm}$ for February 2017, respectively. The maximum standard deviation of rainfall for Peninsular zone was found to be $9.61 \mathrm{~mm}$ in 2018, whereas the minimum value was $0.10 \mathrm{~mm}$ in 2017 . The maximum and minimum value of the coefficient of variation of rainfall was found to be 609.76 in 2018 and 175.12 in 2018, respectively (Table 5). Figure 3a and b shows the precipitation data before the lockdown and during the period of lockdown.

On the other hand, the NE zone was found to have $38.6{ }^{\circ} \mathrm{C}$ as the maximum temperature for April 2019 and $-11.1{ }^{\circ} \mathrm{C}$ as the minimum temperature for January 2016. The maximum and minimum standard deviation of temperature for this zone was found to be $6.8{ }^{\circ} \mathrm{C}$ in 2016 and $2.1^{\circ} \mathrm{C}$ in 2018 , respectively. The maximum and minimum values of the coefficient of variation of temperature were found to be 29.1 in 2016, 2019 and 9.5 in 2018, respectively (Table 11). A maximum monthly average temperature of $33.5^{\circ} \mathrm{C}$ for May 2019 was seen in the $\mathrm{NW}$ zone whereas, the minimum temperature was found to be $10.4{ }^{\circ} \mathrm{C}$ for January 2018 . The maximum and minimum standard deviations of temperature were found to be $12.7{ }^{\circ} \mathrm{C}$ in 2015 and $10.4{ }^{\circ} \mathrm{C}$ in 2018 , respectively. The maximum and minimum value of the coefficient of variation of temperature was found to be 87.0 in 2015 and 35.1 in 2016, respectively (Table 9). The central zone was observed to have a maximum monthly average temperature of $40.0{ }^{\circ} \mathrm{C}$ for May 2016 and $22.3{ }^{\circ} \mathrm{C}$ for January 2017 and 2018 . The standard deviation of maximum temperature was found to be $3.0^{\circ} \mathrm{C}$ in 2020 and minimum temperature $1.9^{\circ} \mathrm{C}$ in 2015,2017 , and 2020 for central zone. The maximum and minimum value of the coefficient of variation of temperature was found to be 16.3 in 2020 and 6.3 in 2015, 2016, and 2017, respectively (Tables $8,9,10)$. The maximum monthly average temperature for the Peninsular zone was observed to be $39.4^{\circ} \mathrm{C}$ for May 2016, while the minimum monthly average 


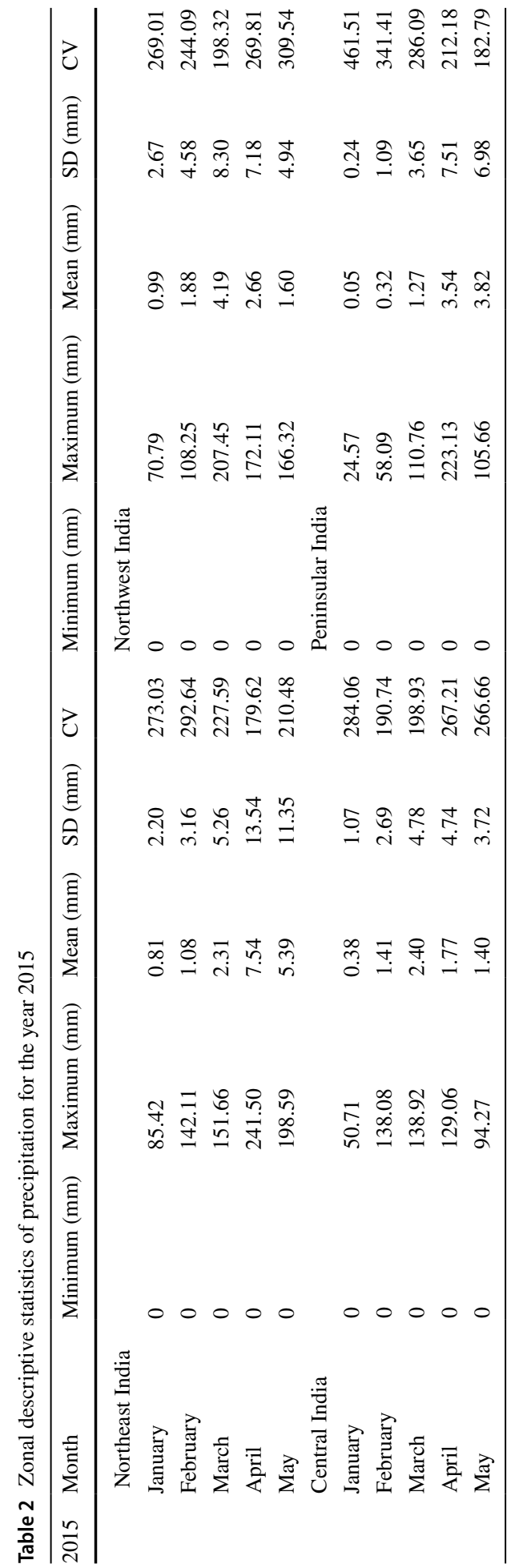




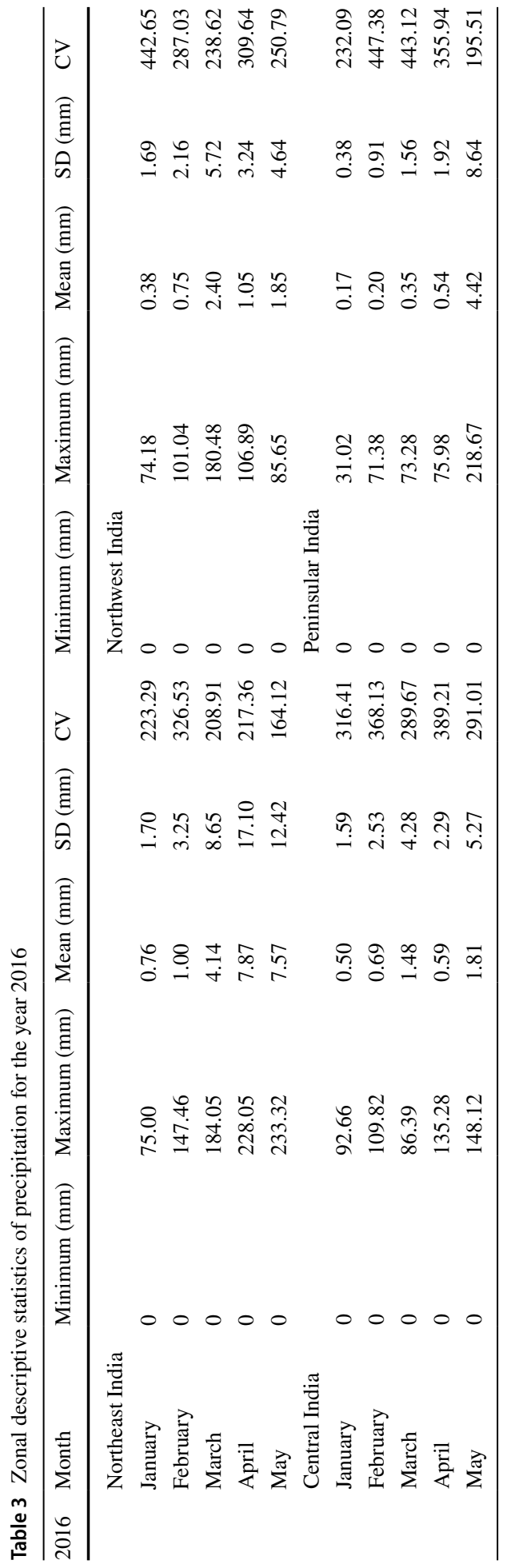




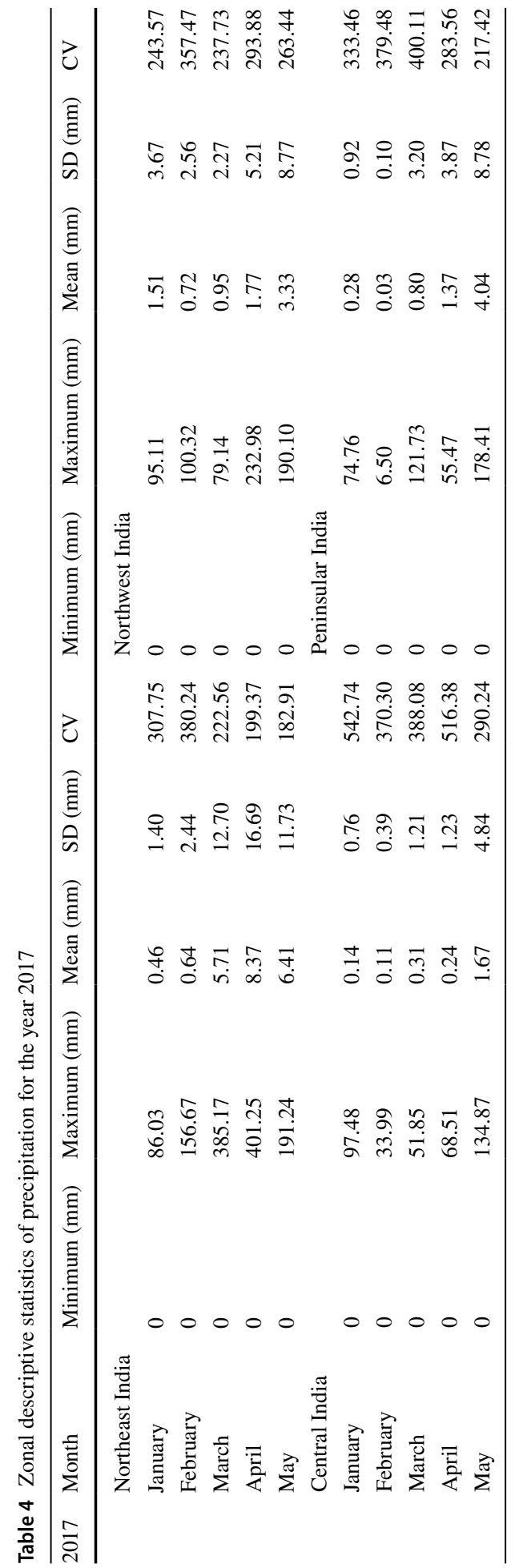



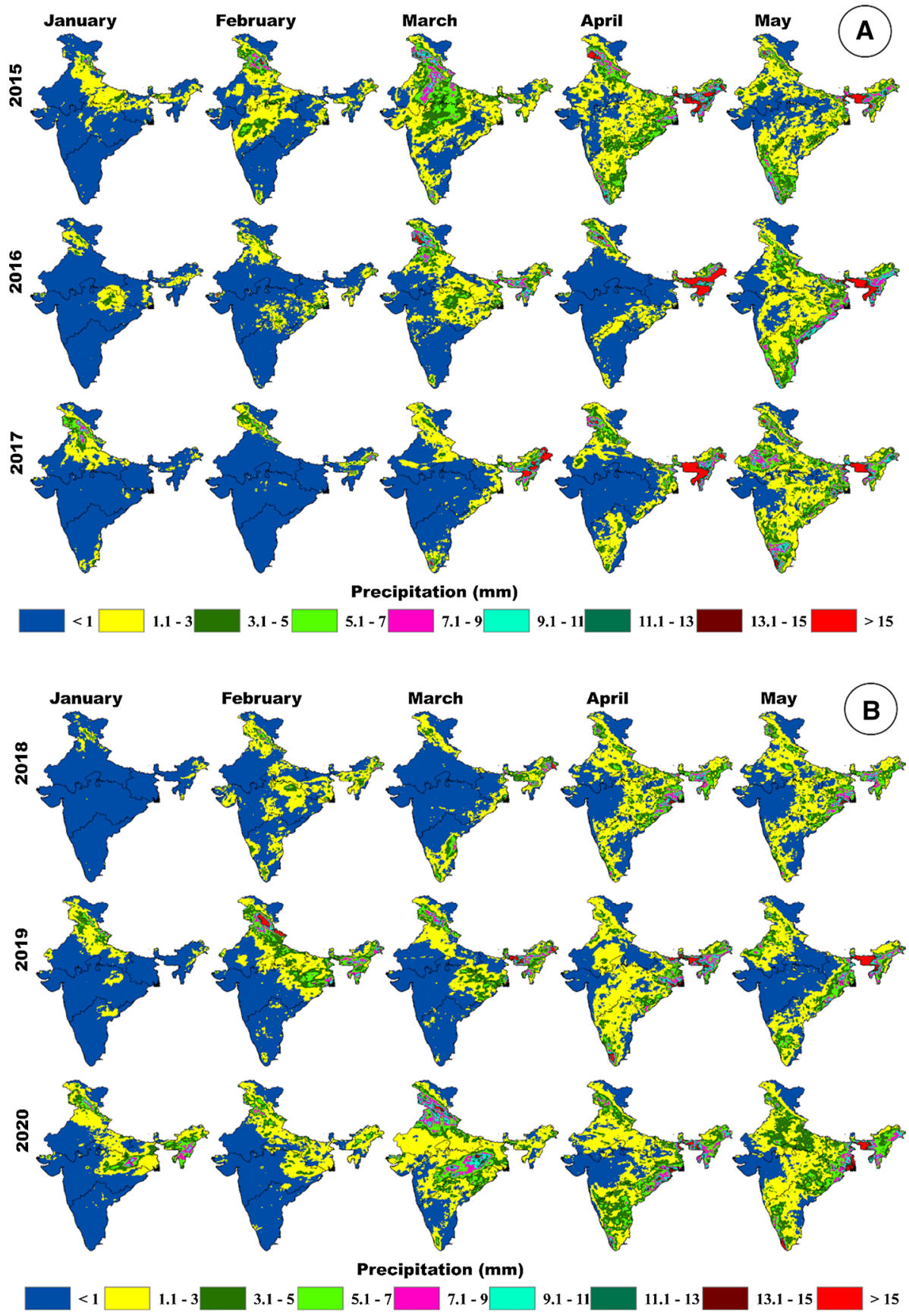

Fig. 3 Meteorological subdivision-wise spatial variations monthly rainfall pattern a year 2015, 2016 and 2017, b year 2018, 2019 and 2020 


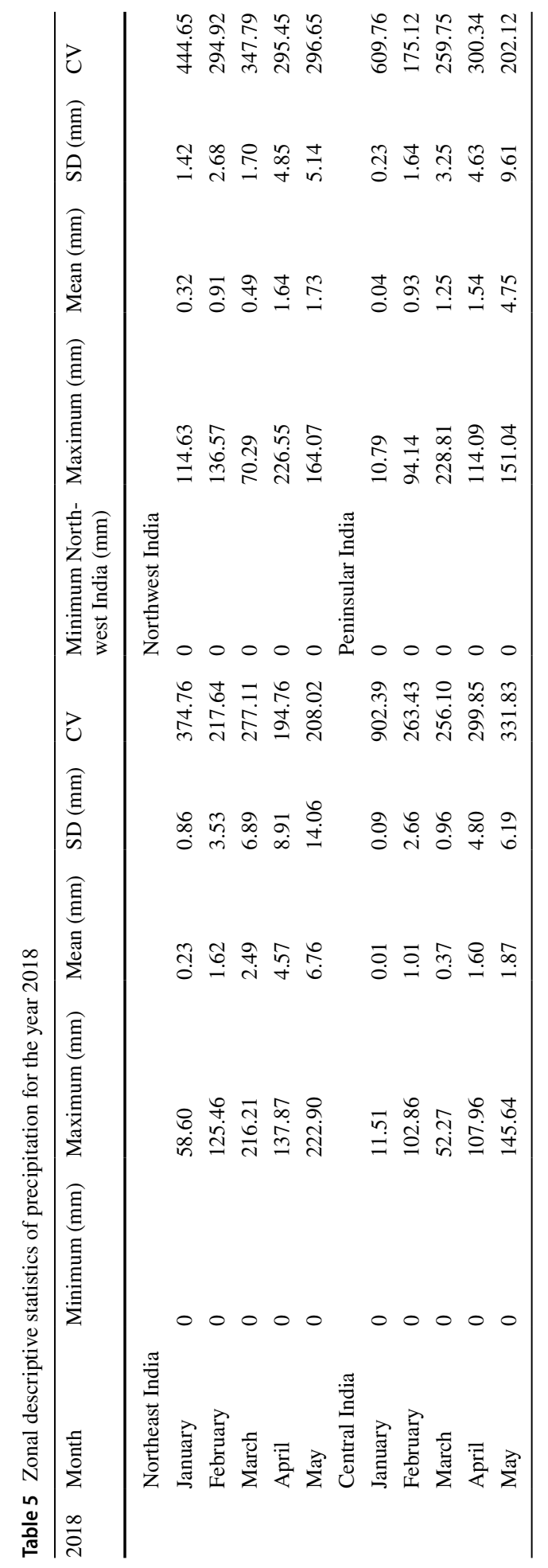




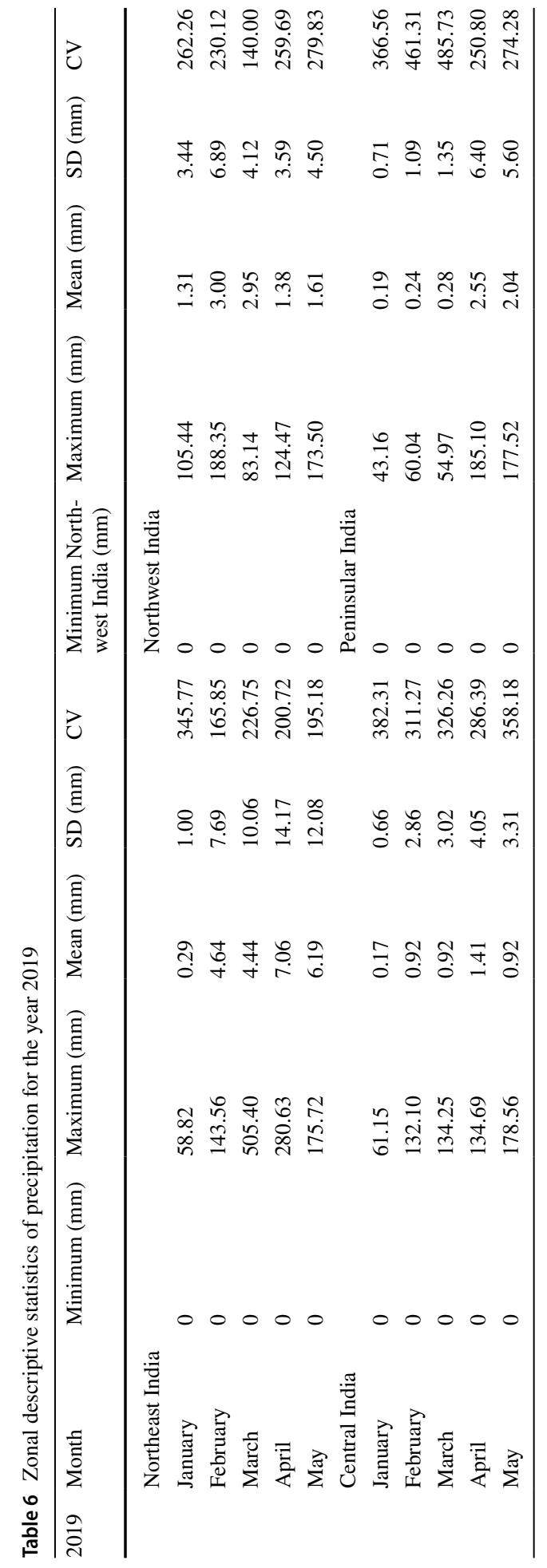




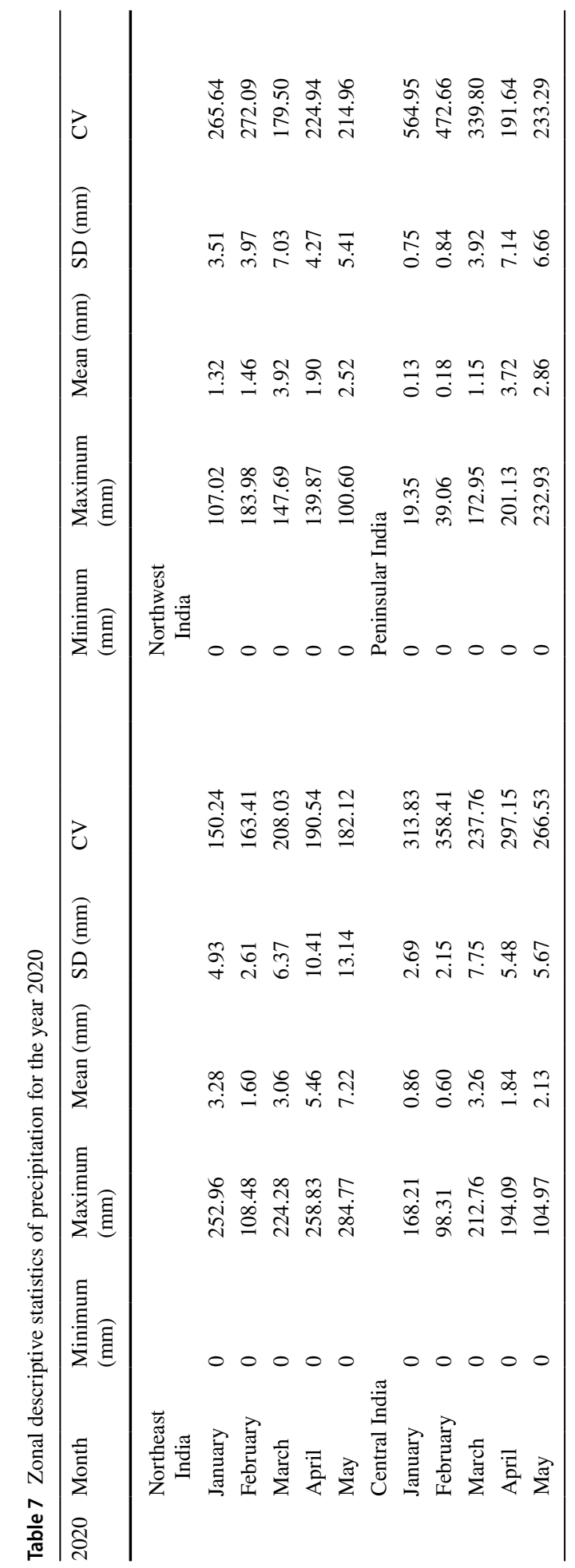



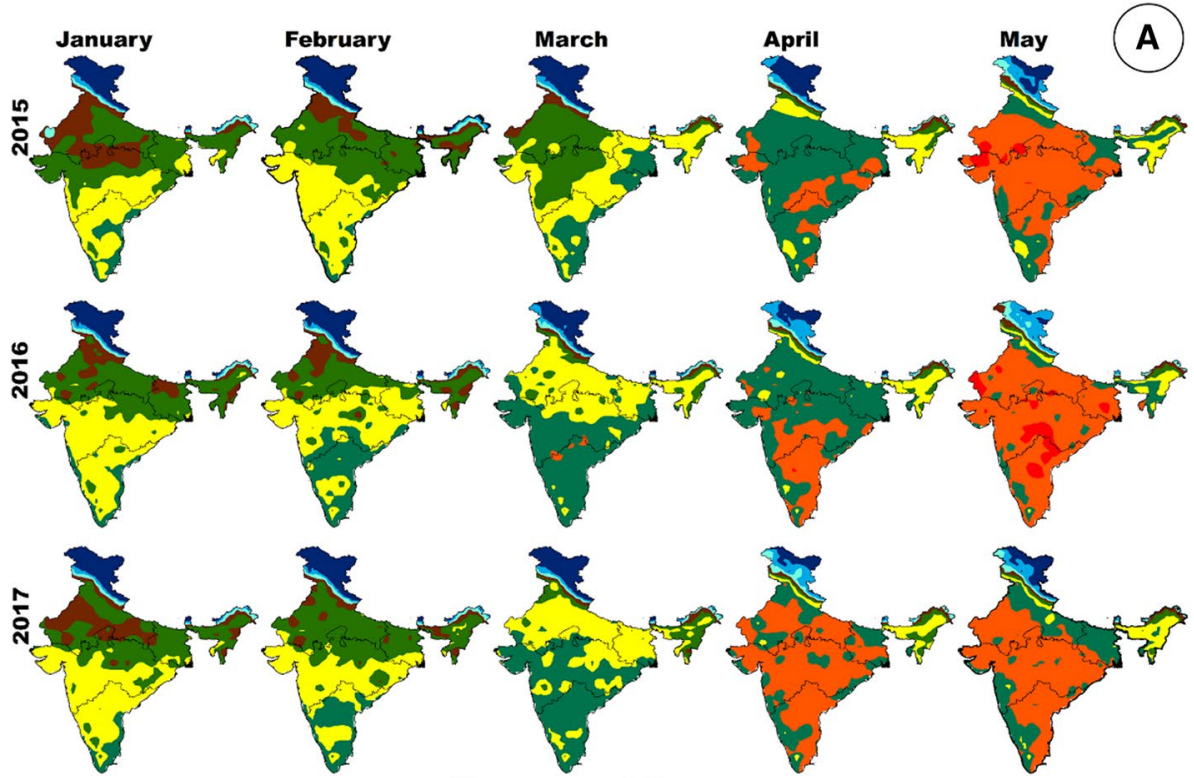

Tempareture $\left({ }^{\circ} \mathrm{C}\right)$

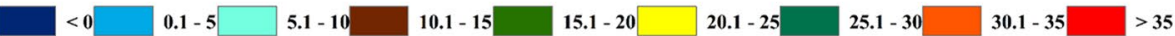
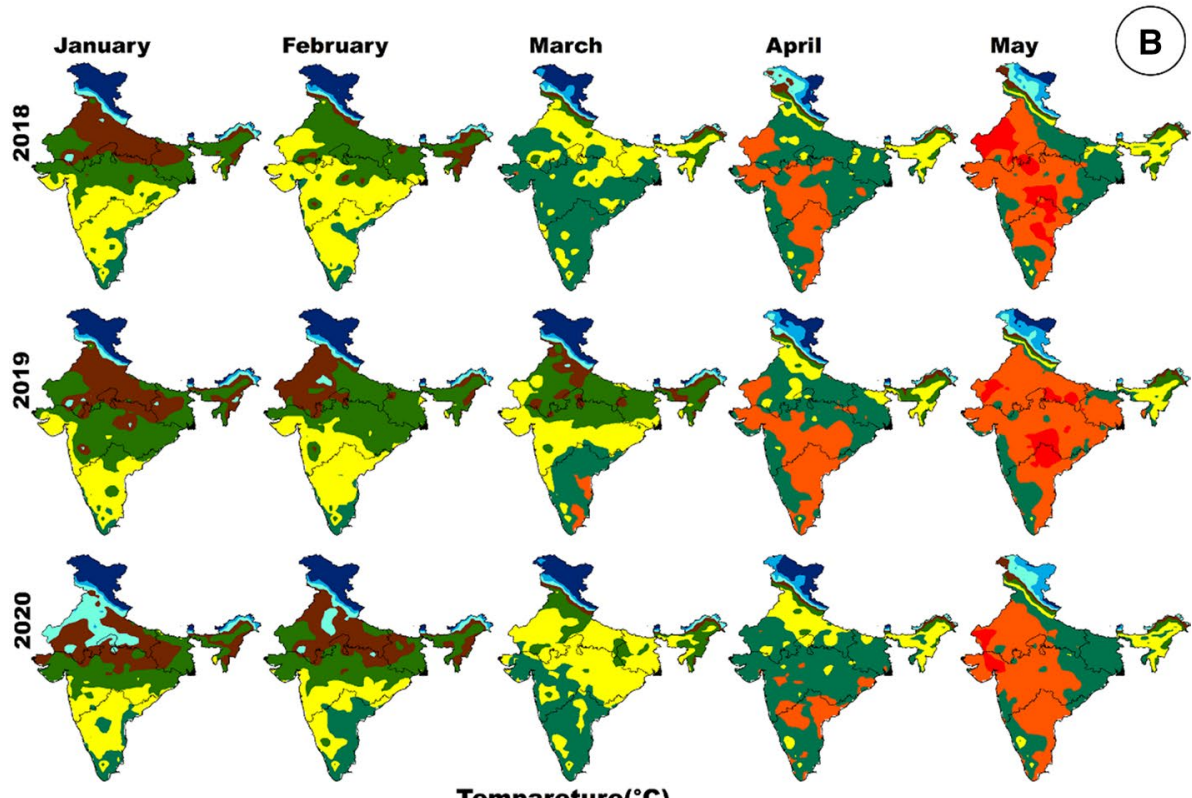

Tempareture $\left({ }^{\circ} \mathrm{C}\right)$

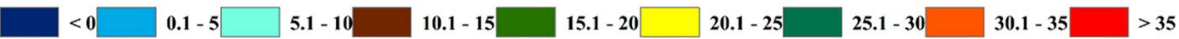

Fig. 4 Meteorological subdivision-wise spatial variations monthly temperature pattern a year 2015, 2016 and 2017, b year 2018, 2019 and 2020 


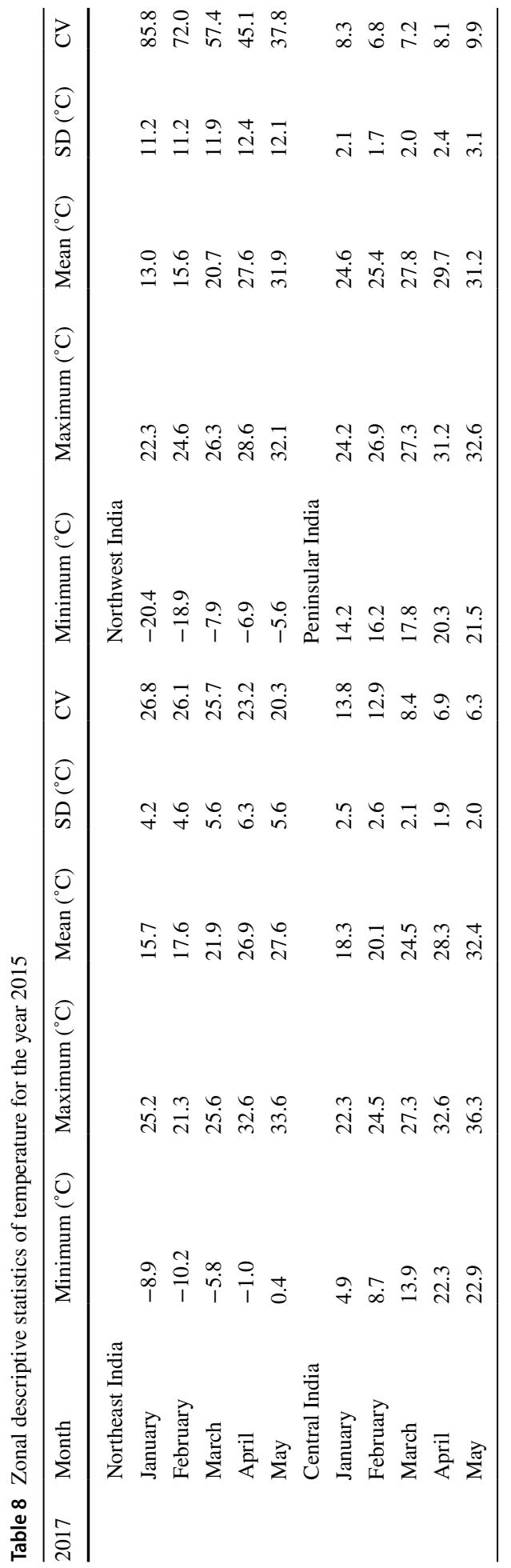




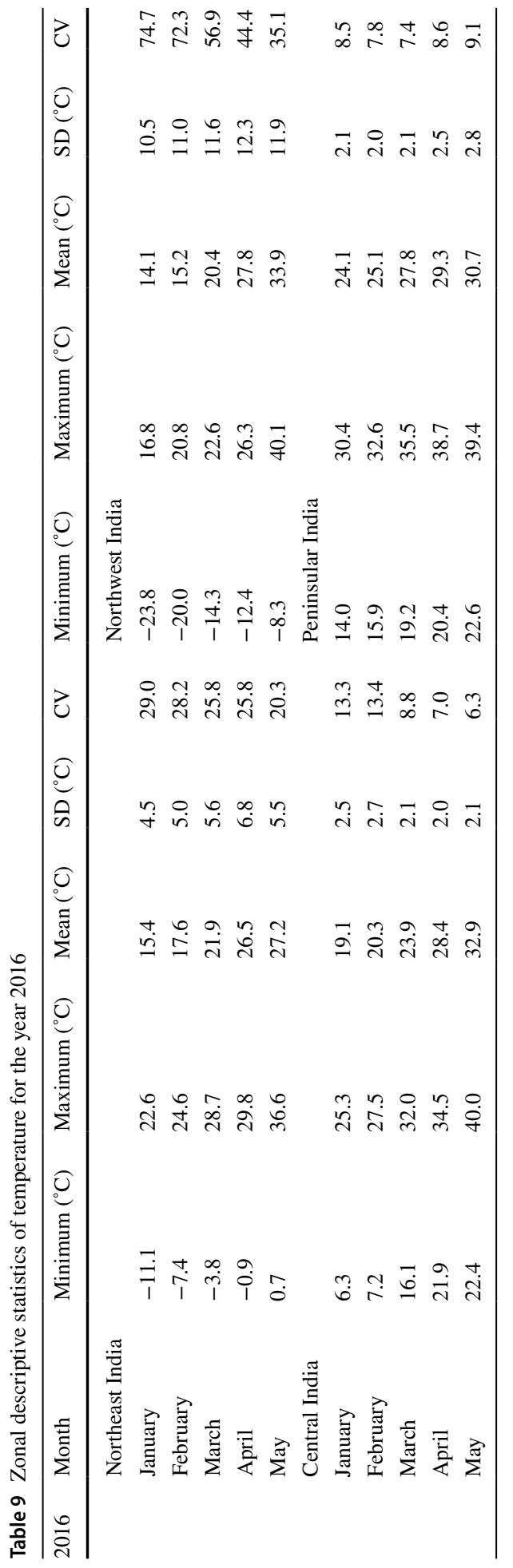




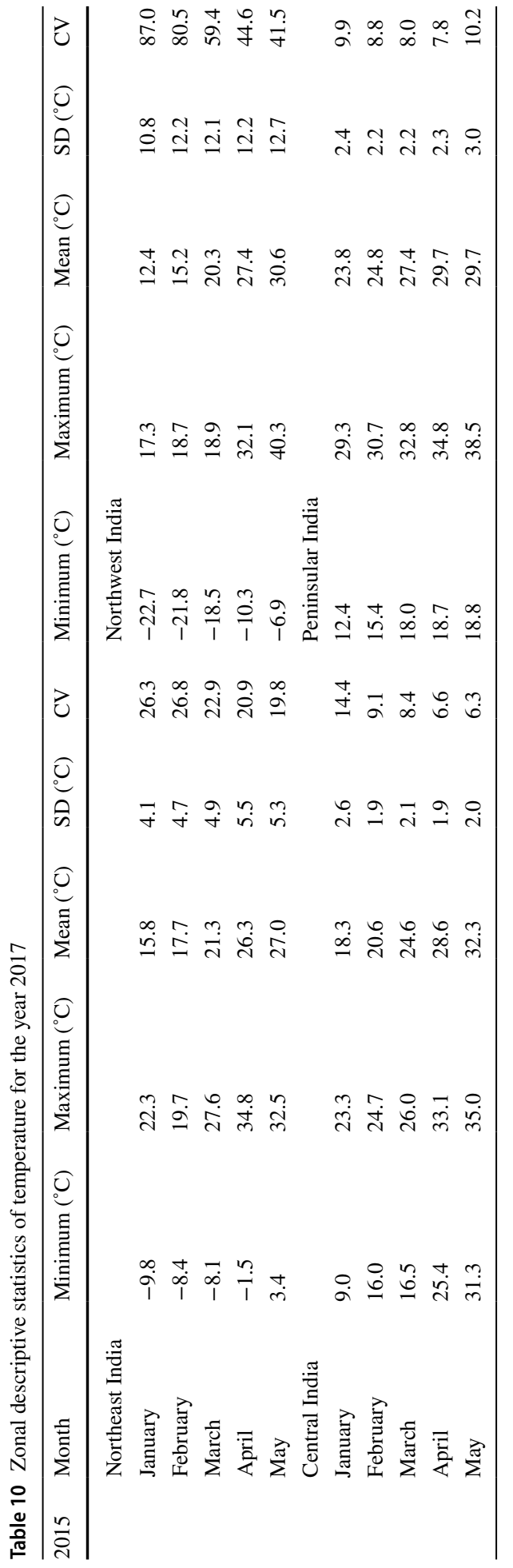




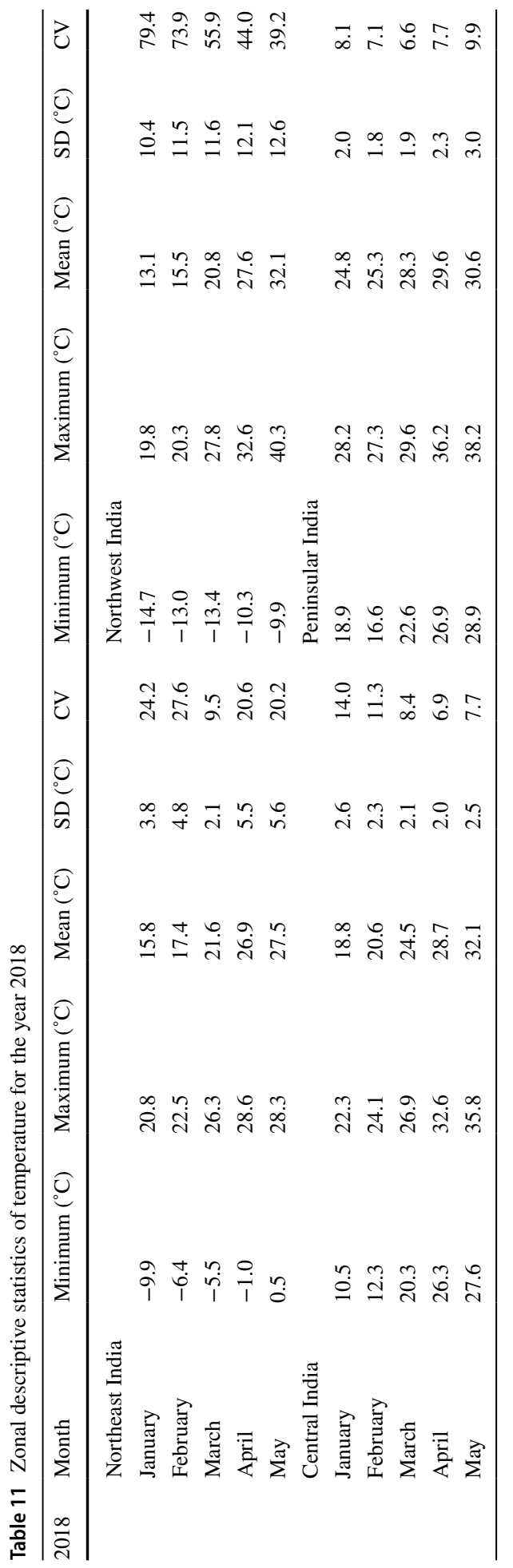




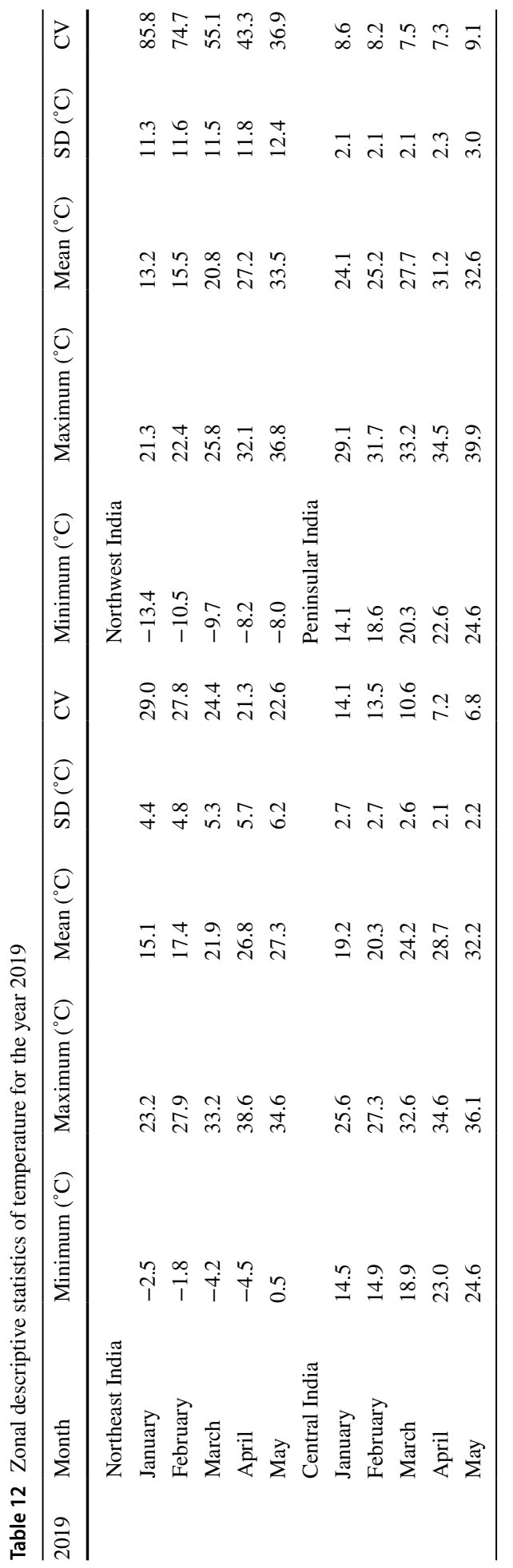




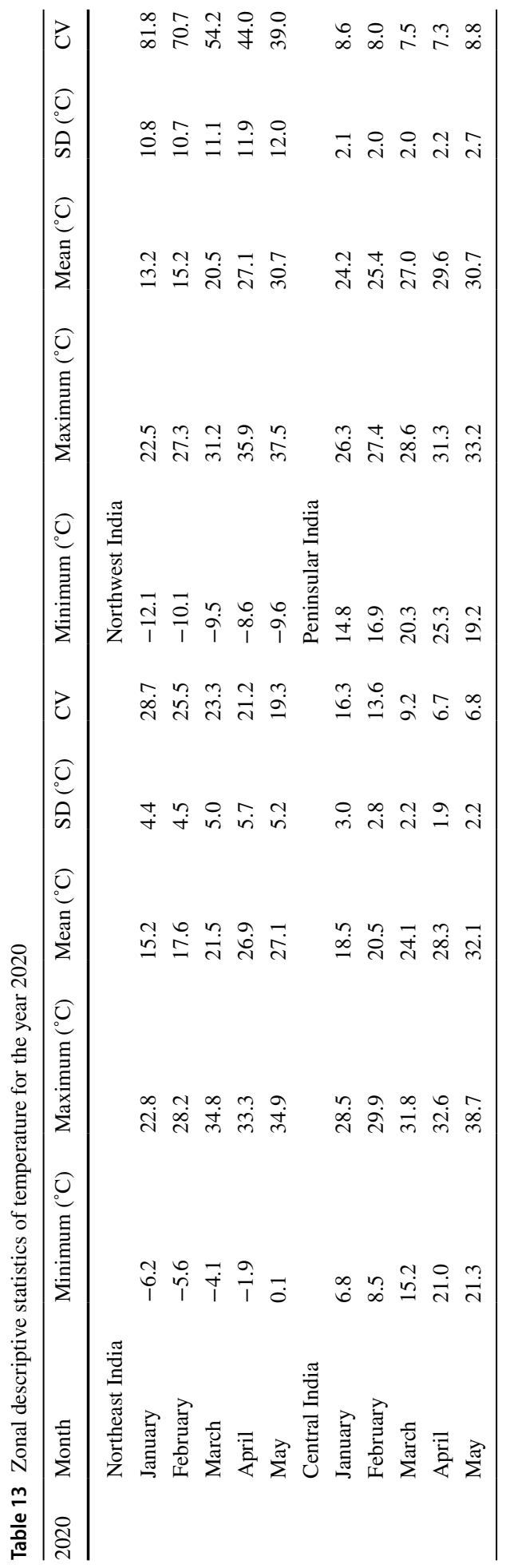


temperature was recorded as observed to be $12.4{ }^{\circ} \mathrm{C}$ for January 2015 . The maximum and minimum standard deviations of temperature for this zone were found to be $3.1{ }^{\circ} \mathrm{C}$ in 2017 and $1.7{ }^{\circ} \mathrm{C}$ in 2017 , respectively. The maximum and minimum value of the coefficient of variation of temperature was found to be 10.2 in 2015 and 6.6 in 2018 , respectively (Tables 8 and 9). Figure $4 \mathrm{a}$ and $\mathrm{b}$ shows the temperature data before the lockdown and during the period of lockdown.

\subsection{SPC I-Chart for precipitation and EWMA chart for temperature}

The zonal daily average of rainfall for individual month and zonal daily average of temperature is presented in the I-Charts in Figs. 5, 6, 7 and 8 and EWMA charts in Figs. 9, 10, 11 and 12, respectively. As per the mentioned rules, the study reveals whether the rainfall and the temperature are "out of control" for a specific zone, month, and year. The out of control situation specifies the presence of non-random variations in the process or in other words, the out of control situation indicates assignable causes that may be present in the process and make the process become statistically unstable. Therefore, further investigation is essential to identify the assignable causes, take measures to remove them and make the process to retain its stability (Şengöz 2018). In our study, the out of control situations for rainfall were found in January 2017 and 2020, April and May 2016 (Fig. 5) for NE zone, January 2017 and 2019 (Fig. 6) for NW zone, March, April, and May 2015 for central zone and February, March 2018, April 2015 and 2017 for peninsular zone (Figs. 7 and 8).

For temperature the out of control situations were identified in January-2015, 2016, 2019, 2020, February-2016, 2017, 2019, 2020, March-2015, 2016, 2018 to 2020, April-2015, 2017 to 2020, May-2015, 2016, 2019 and 2020 for NE zone (Fig. 9), January-2017, 2020, February-2016, 2018, 2020, March-2015, 2016, 2018, 2019, April-2017, 2019, 2020, May, 2017, 2019 and 2020 (Fig. 10) for NW zone, January-2015, 2016, 2019, 2020, February-2016, 2019, 2020, March-2015, 2017 to 2019, April-2016, 2018, May-2017, 2018 to 2020 (Fig. 11) for central zone and January-2015 to 2018 and 2020, February-2015 to 2017, 2020, March-2015, 2017, 2020, April-2016, 2018 to 2020, May-2016, 2018 to 2020 (Fig. 12) for peninsular zone. 


\section{North-east Zone}

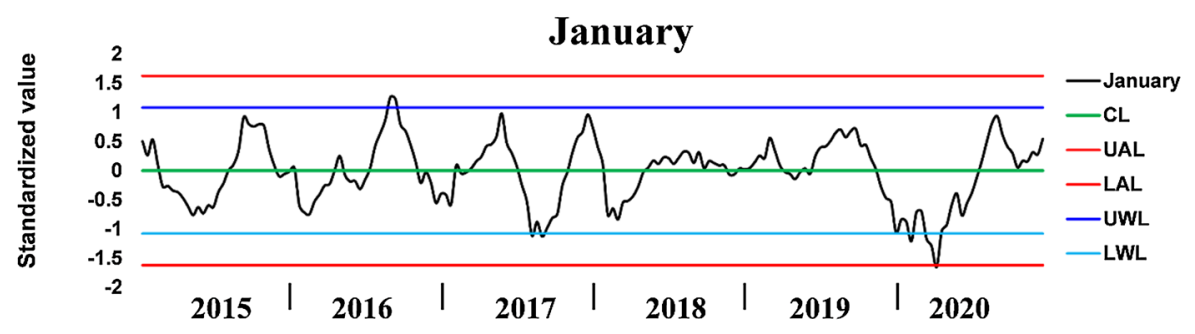

February
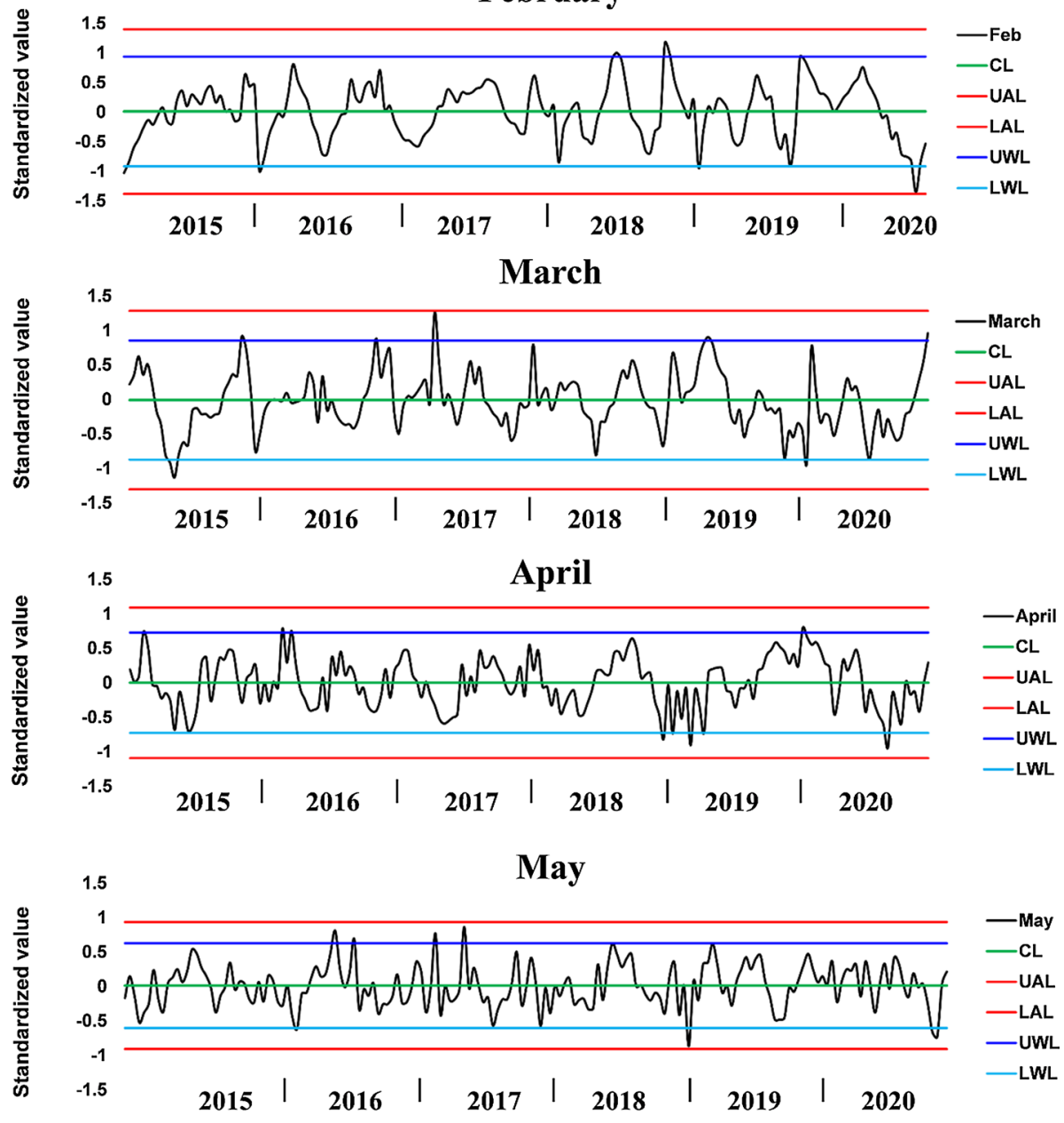

Fig. 5 SPC I-Chart of monthly precipitation in northeast zone 


\section{North-west Zone}

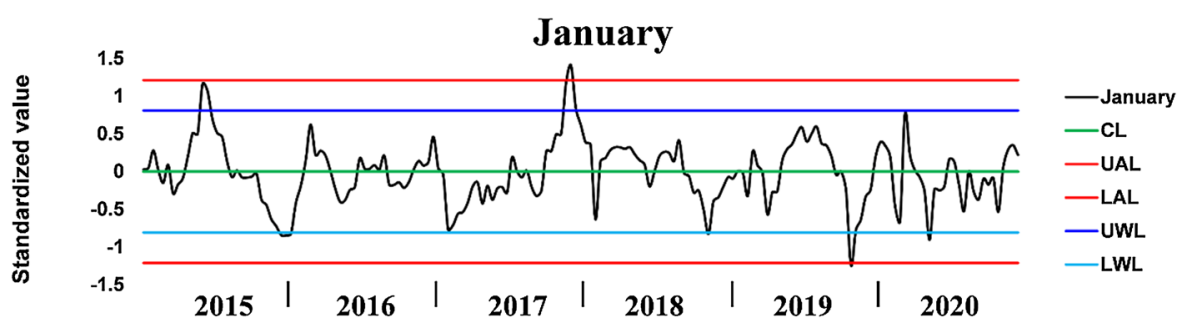

February

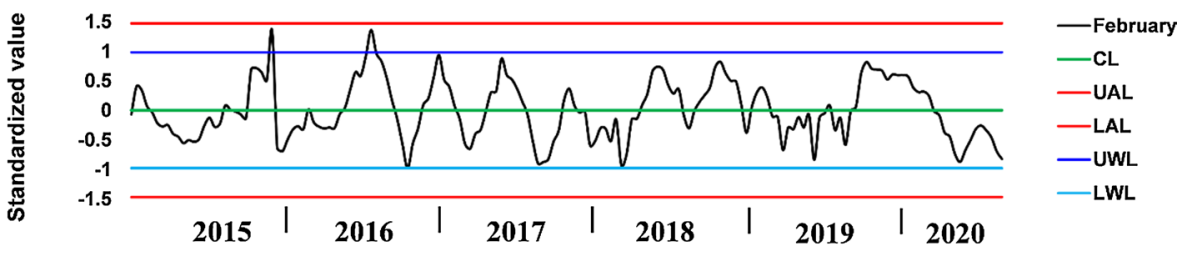

\section{March}

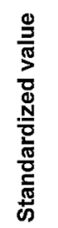

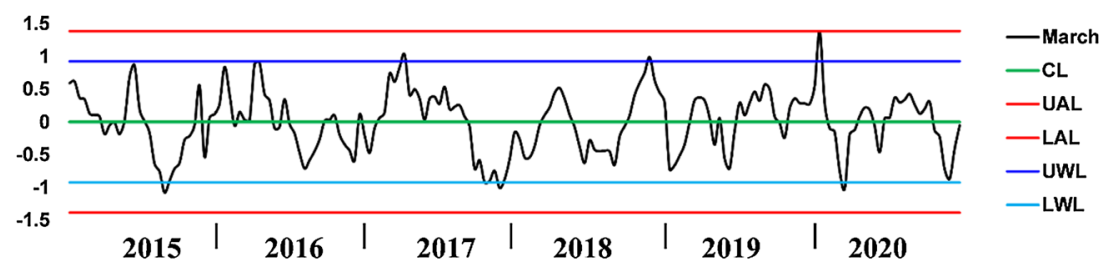

April

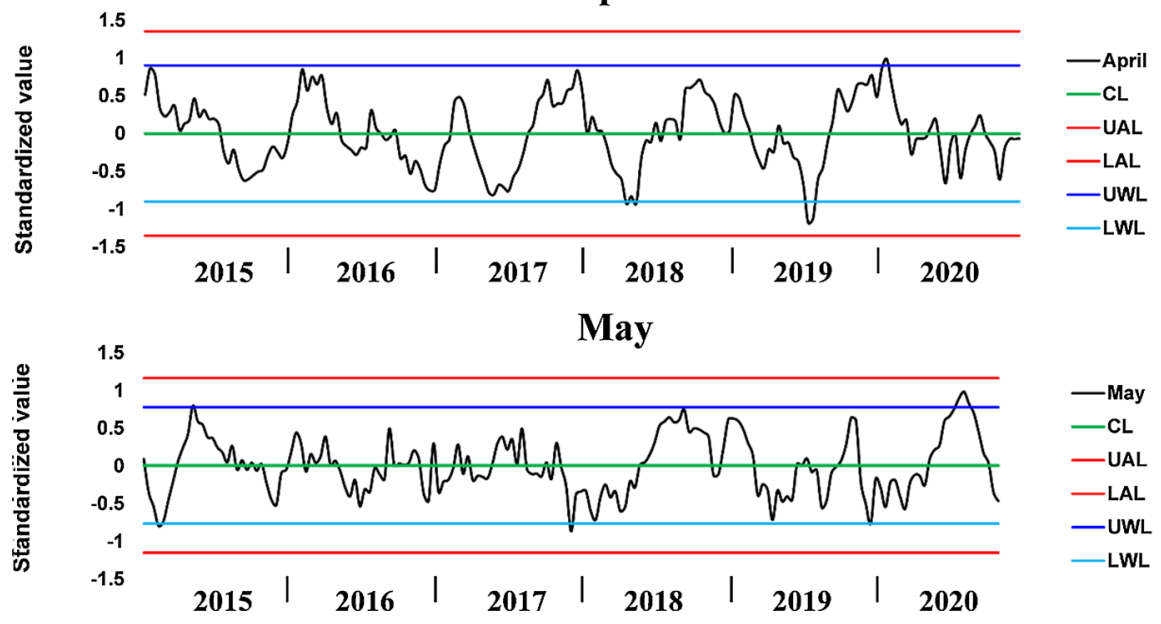

Fig. 6 SPC I-Chart of monthly precipitation in northwest zone 


\section{Central Zone}

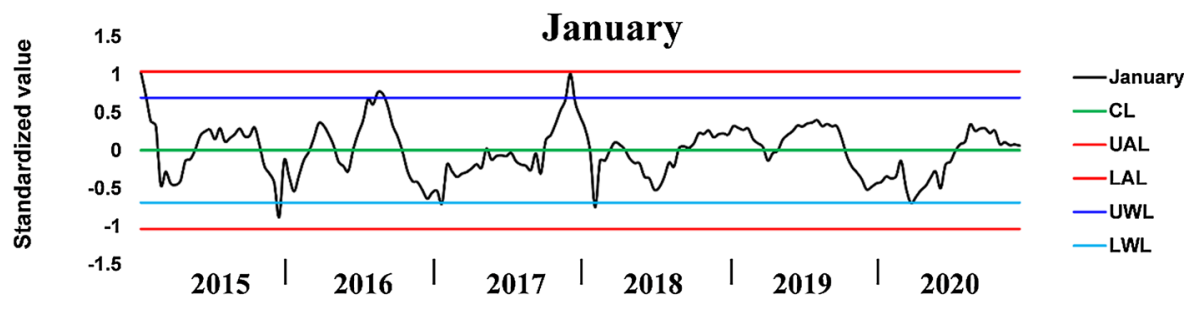

\section{February}

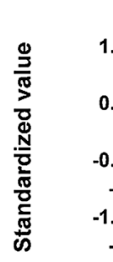

2
1.5
1
0.5
0
-0.5
-1
1.5
-2
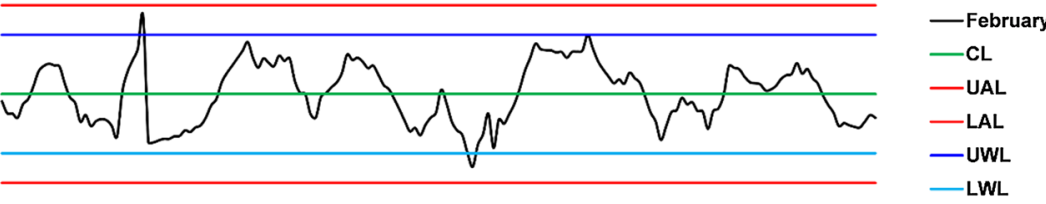

\begin{tabular}{l|l|l|l|l|l|l}
2015 & 2016 & 2017 & 2018 & 2019 & | & 2020
\end{tabular}

March
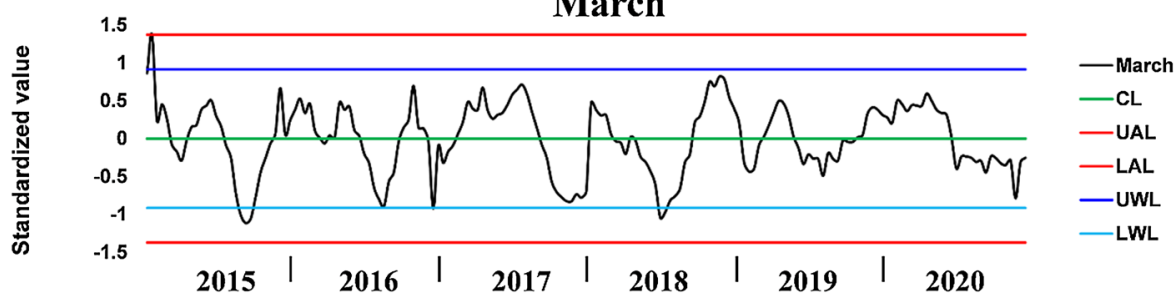

April

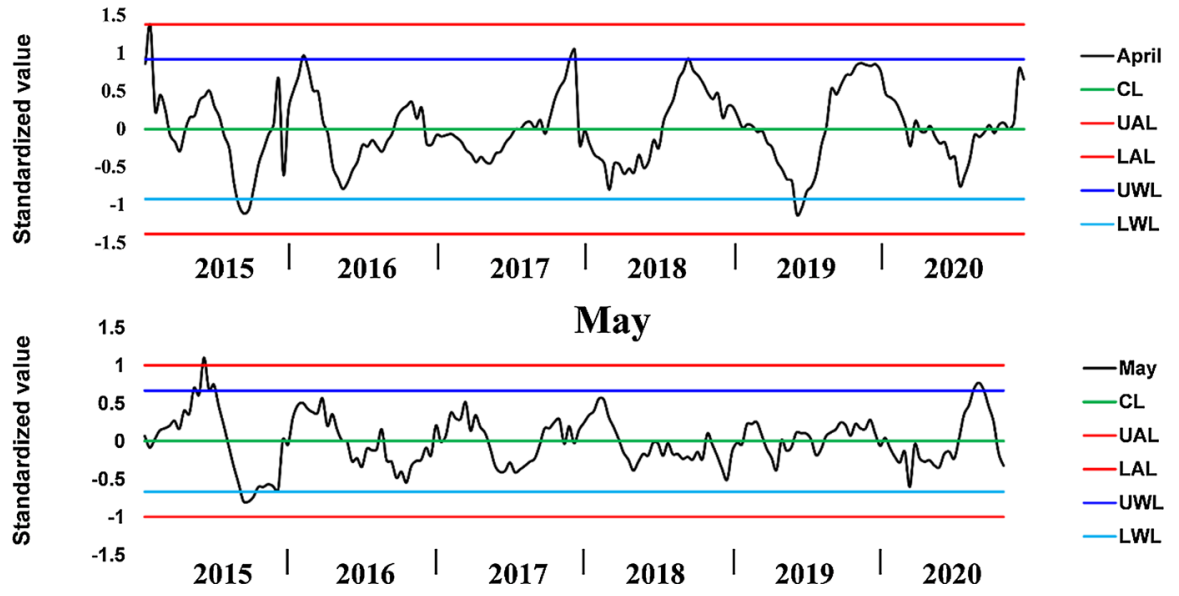

Fig. 7 SPC I-Chart of monthly precipitation in central zone 


\section{Peninsular Zone}

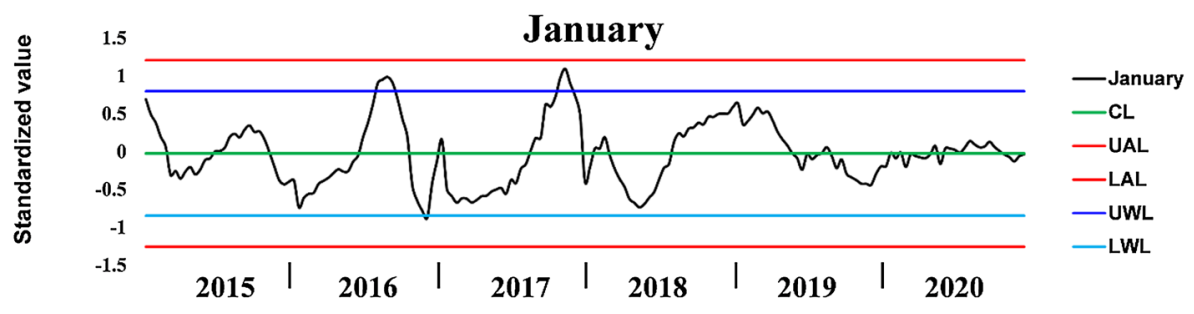

\section{February}
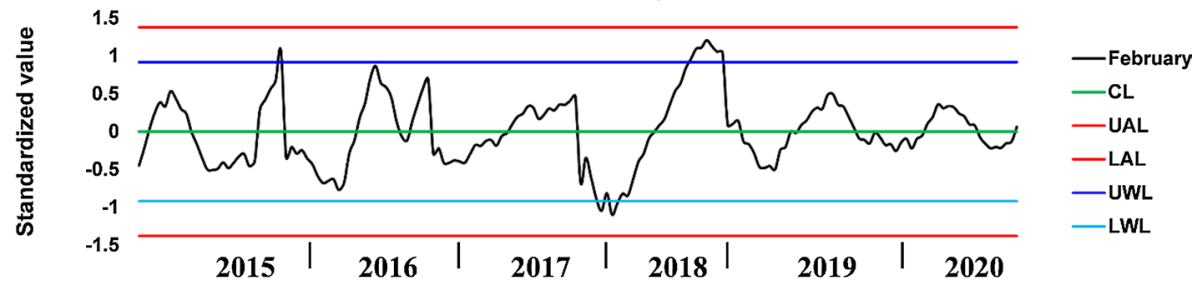

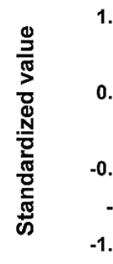

\section{March}
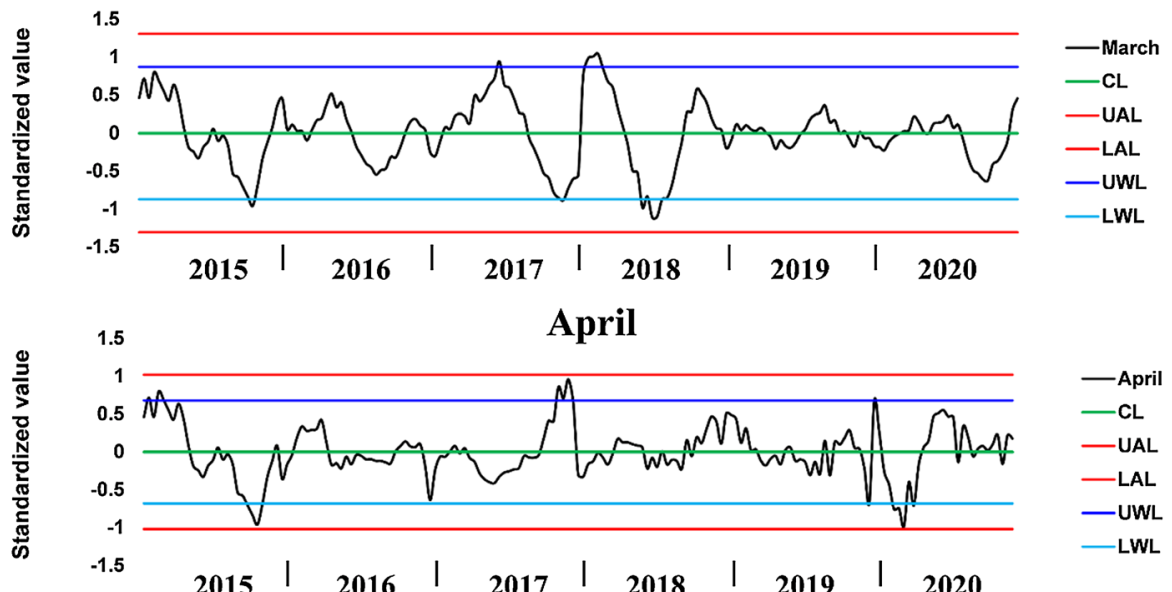

\section{April}

1.5

1

0

$-0.5$

$-1$

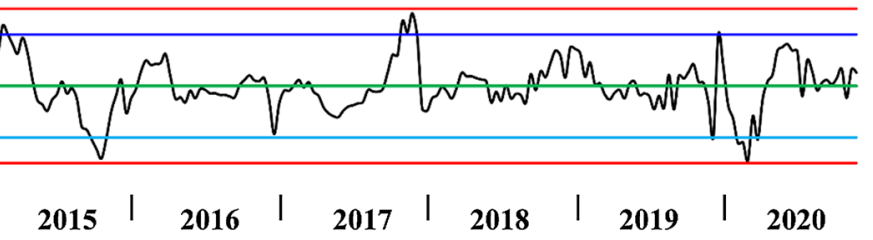

- April
- CL
- UAL
- LAL
- UWL
- LWL

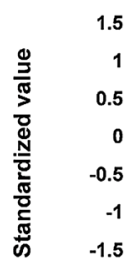

May

1

$M \sqrt{1}$

$-1$

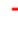

$$
\begin{array}{lllllllllll}
2015 & 2016 & \text { | } & 2017 & 2018 & \text { | } & 2019 & \text { | } & 2020
\end{array}
$$

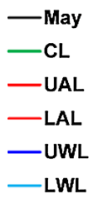

Fig. 8 SPC I-Chart of monthly precipitation in peninsular zone 


\section{North-east Zone}
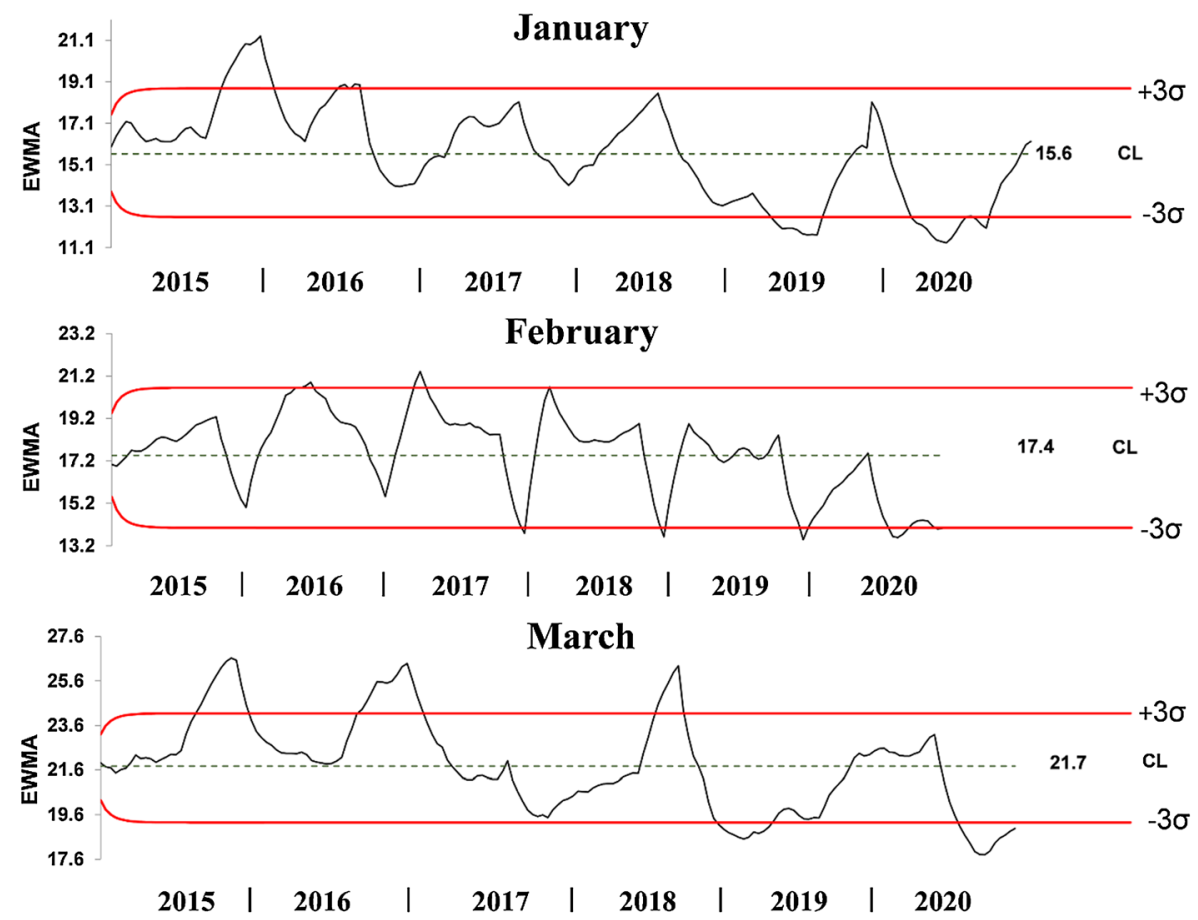

April
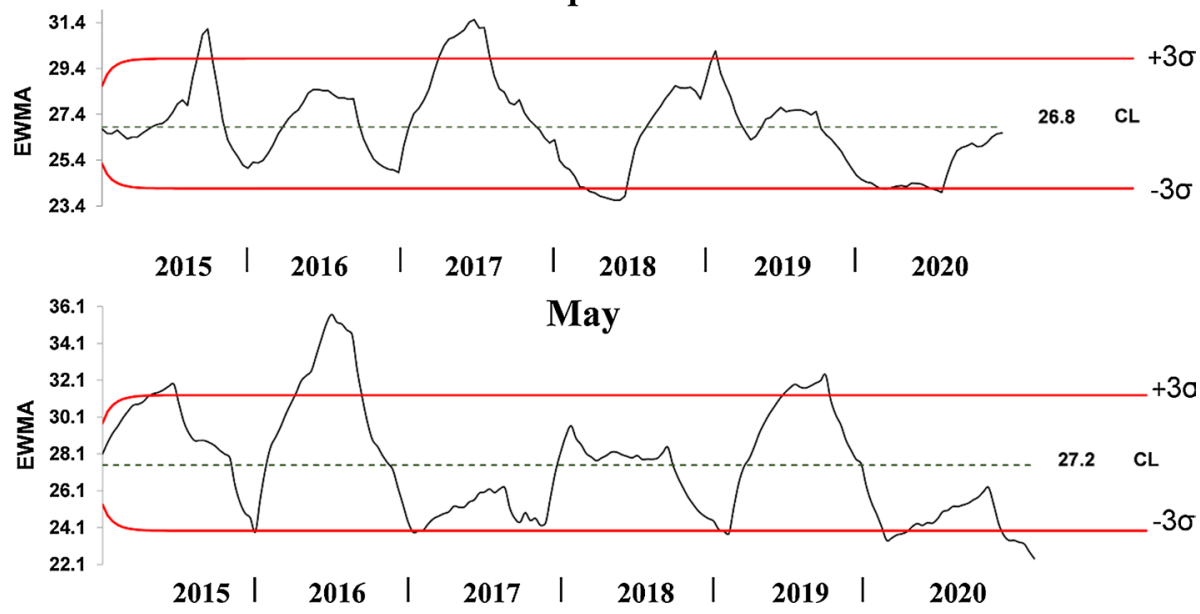

Fig. 9 EWMA control chart for monthly temperature in northeast zone 


\section{North-west Zone}

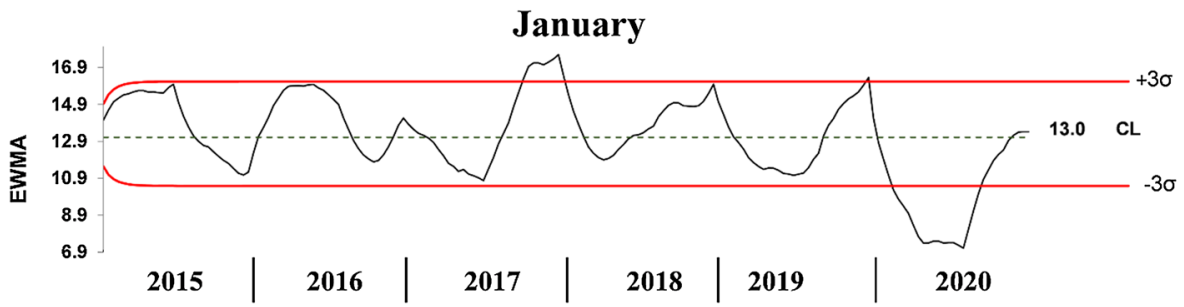

February

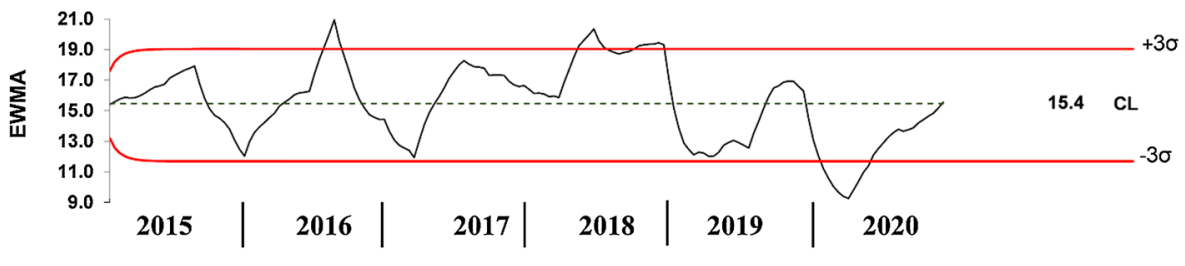

March
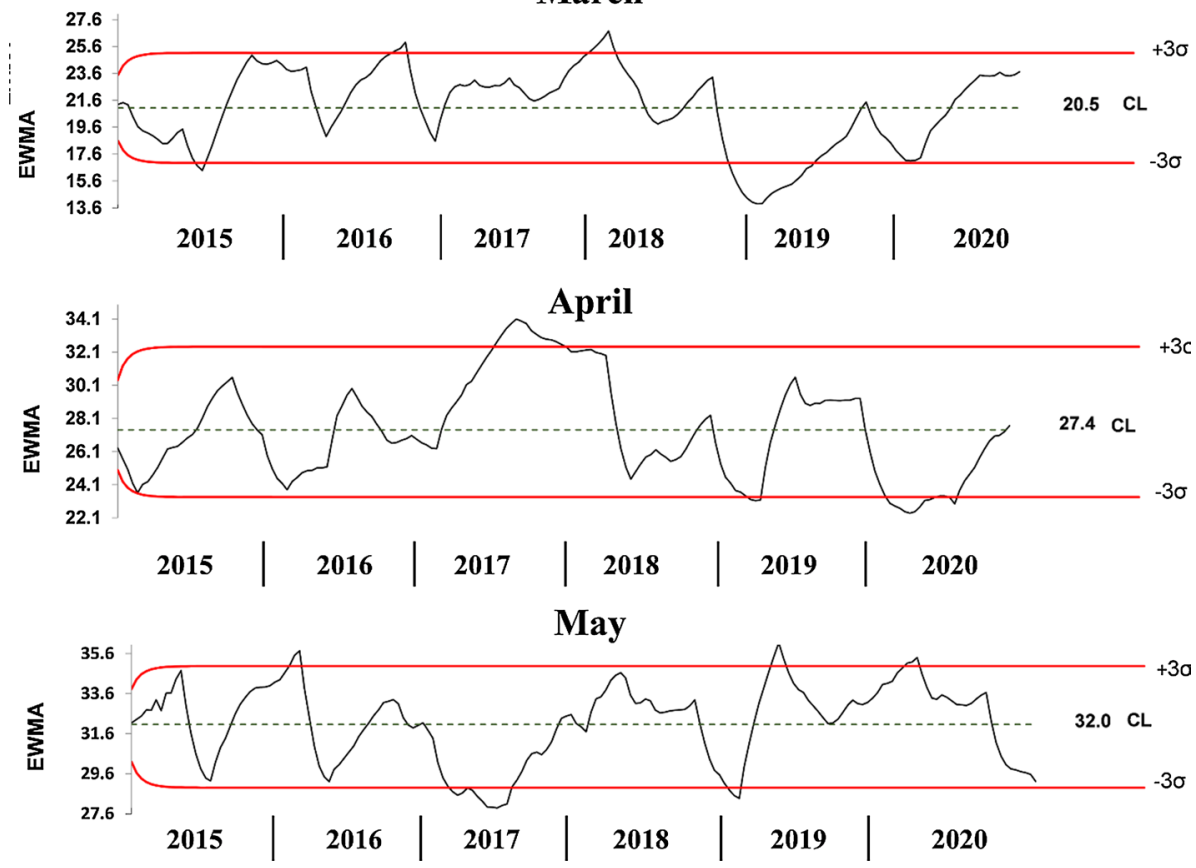

Fig. 10 EWMA control chart for monthly temperature in northwest zone 


\section{Central Zone}

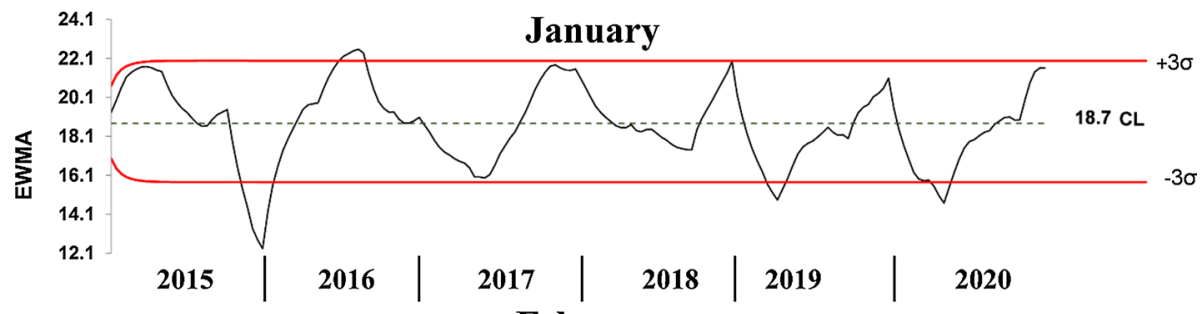

February
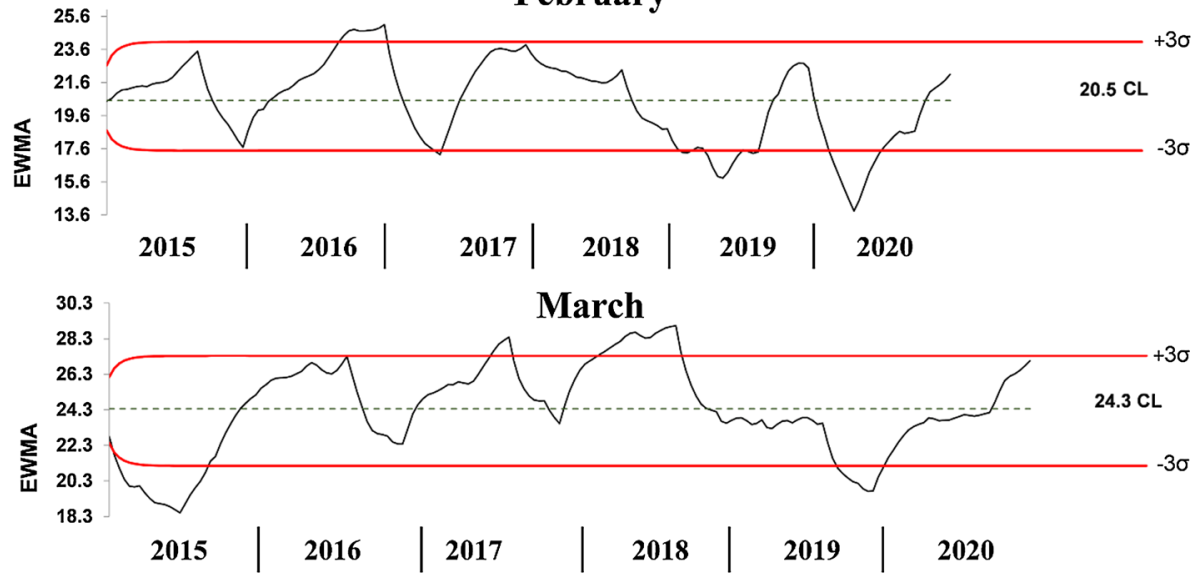

April
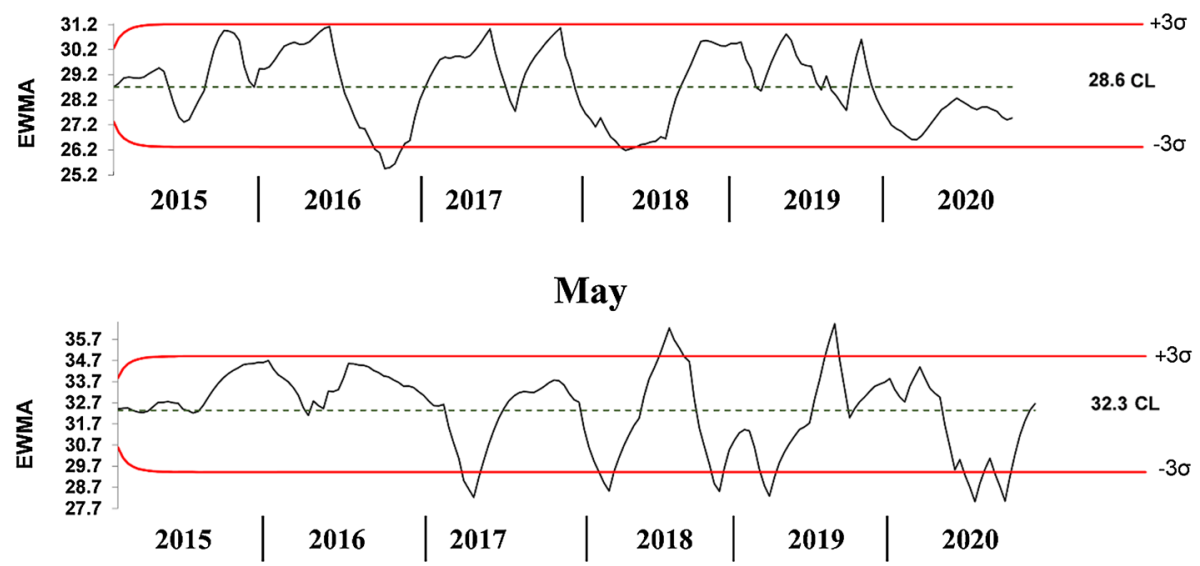

Fig. 11 EWMA control chart for monthly temperature in central zone 


\section{Peninsular Zone}
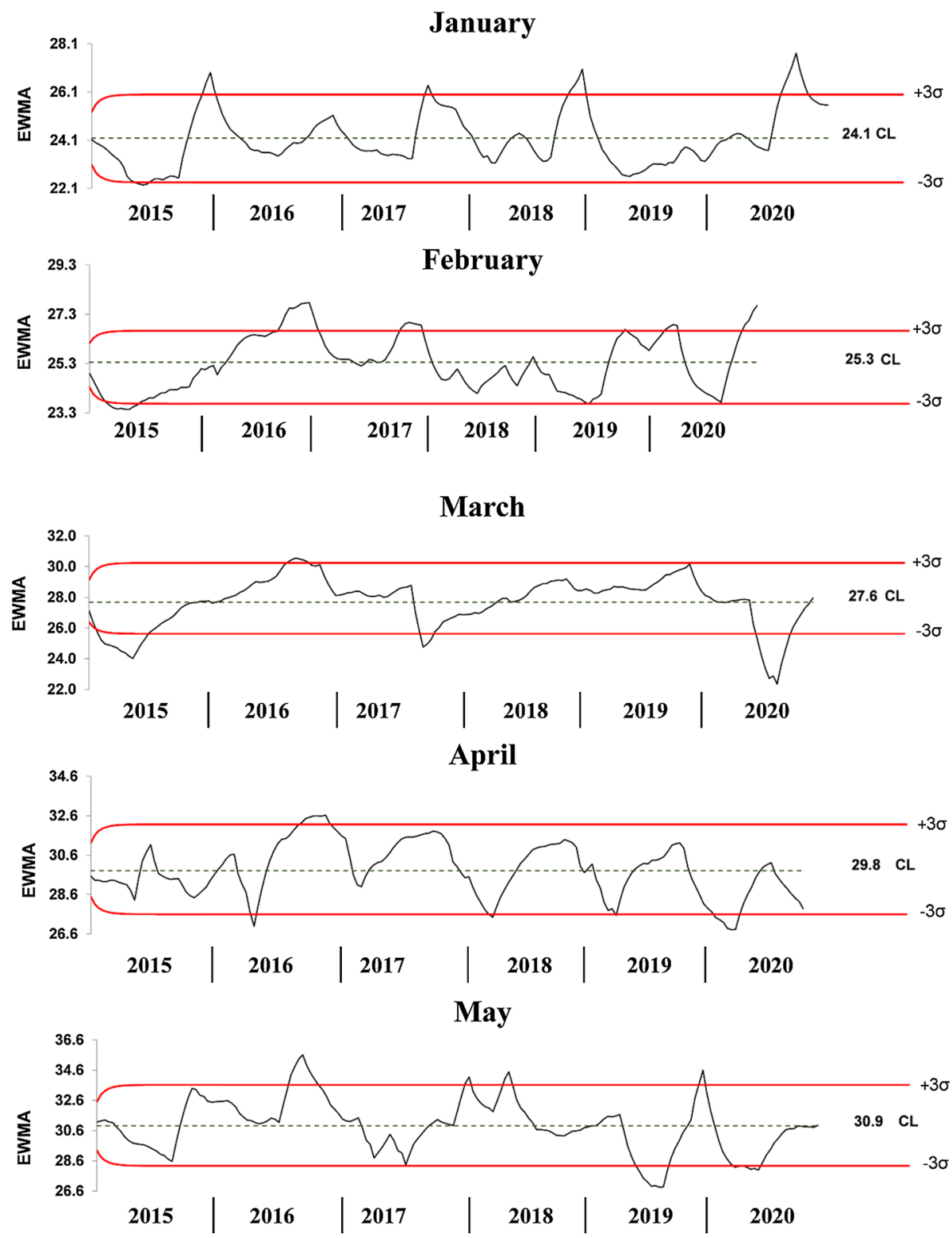

Fig. 12 EWMA control chart for monthly temperature in peninsular zone 


\subsection{Assessment of spatial relationships}

The correlation coefficient between rainfall and temperature was estimated for each grid to find the association between them. In summer, correlation between temperature and precipitation is usually significant and always negative. This means that a cool summer is generally accompanied by important precipitation, and vice versa. Significant differences were observed among the all zones. Study reveals that the maximum areal extend of India had a moderate to strong negative correlation ranging between ( -0.3 to -0.7 and -0.7 to -1 ) on March, April, and May 2015 (Fig. 13a). Some pockets of central and peninsular zone were seen to have moderate to strong negative correlation on May 2016. However, these zones were observed to be in a negative relationship also in April and January, March, and January, respectively, in the year of 2016. However, year 2017 was observed with a significant positive as well as negative correlations. The maximum area of India was seen to have a moderate positive association, followed by strong positive relation in the range of 0.3 to 0.7 and 0.7 to 1.0 in January, February, and April. The maximum area of the country was seen to have a moderate negative relation in the month of March, while some portions of NW zone were seen to be in a strong $(-0.7$ to -1$)$ negative relation in 2018 (Fig. 13b). A large area of central, peninsular, and NW zone was found to be in a moderate to strong correlation on February, March, April of this year, while major grids of NE and NW zones were found to be in moderate negative relation on January and February. The months of March, April, and May 2019 were observed to be in a wide range of positive correlation (0.1-1.0) covering the major portion of India, while January and February were identified with low (0 to -0.3 ) to moderate negative relation covering the maximum portion of India. Low to moderate negative correlation was seen to occur mainly in $\mathrm{NE}$ and peninsular zone in May 2020 (Fig. 13b). A moderate to high negative association was seen mainly to cover the maximum area of NW and central and NE zone in February, March, and April, while some pockets of peninsular were also identified with low to moderate negative relation from January to May.

\section{Discussion}

From the above findings, it is clear that a negative correlation might have been responsible for the combination of high temperature and low rainfall value or vice versa, whereas high temperature and high rainfall have resulted in a positive correlation. For example, in the NW and central zone, a rising pattern of the temperature variable was observed where the maximum values of temperature were found to be above the zonal mean monthly temperature and certain rainfall values were found to be above the zonal mean monthly value touching the UWL (Figs. 14, 15). A noticeable increase in average temperature was witnessed specifically in the year 2016 and 2019, especially from March to May. In contradiction, a reduction in the average temperature was observed in 2020 exclusively for April and May. On the other hand, the year 2015 holds the highest rainfall in total after which a certain decrease was noticed till 2018. Although the average rainfall was observed to be increased slightly in 2019, it goes without saying that the mean rainfall in 2020 has been much higher than the previous years, except 2015. Hence, on average, from these outcomes, it can be interpreted that the negative and positive correlations found within the zonal pockets are the combined effect of high temperature and less rainfall, and high 

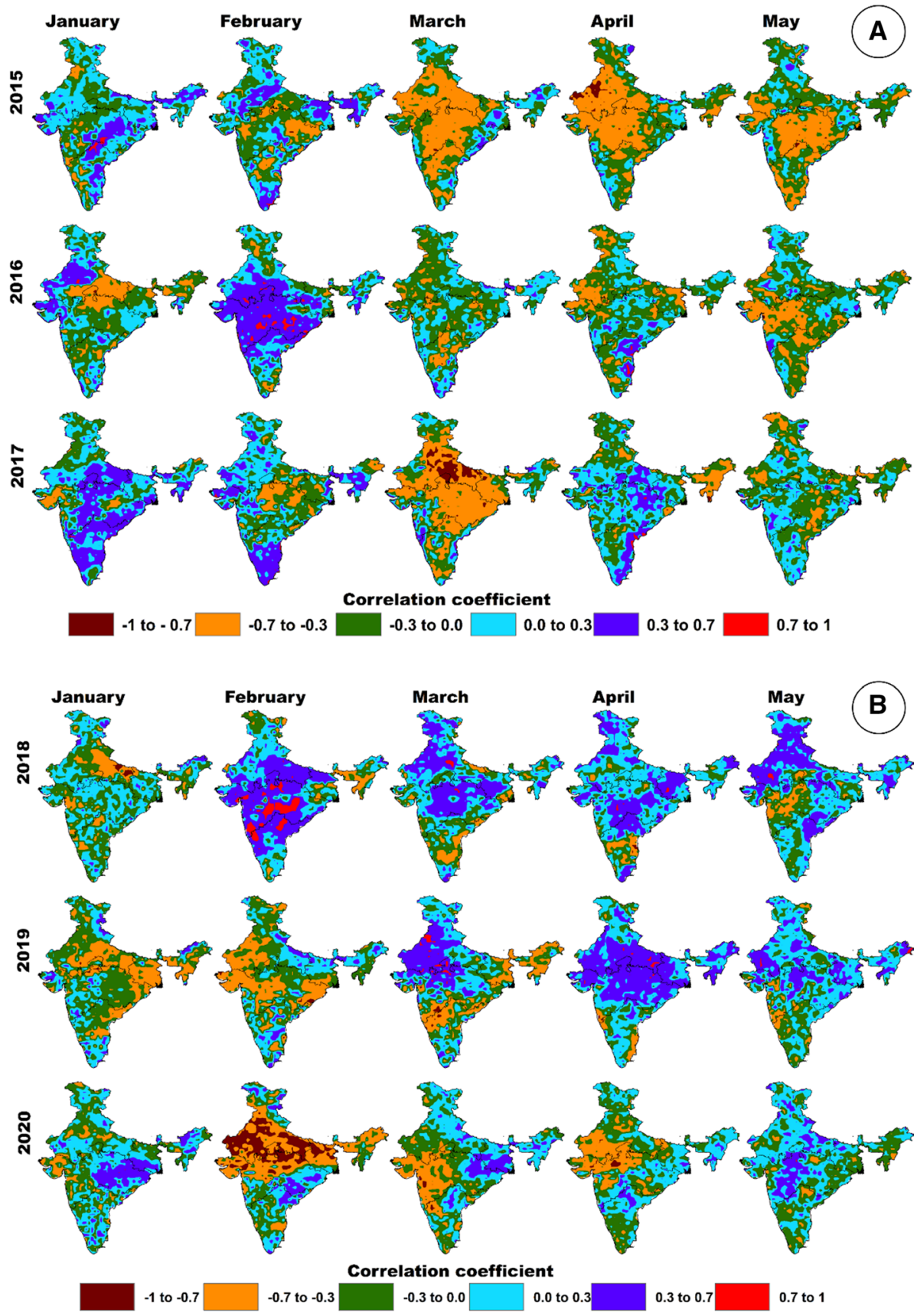

Fig. 13 Meteorological subdivision-wise spatial correlation maps between precipitation and temperature. a Year 2015, 2016, and 2017, b year 2018, 2019, and 2020 


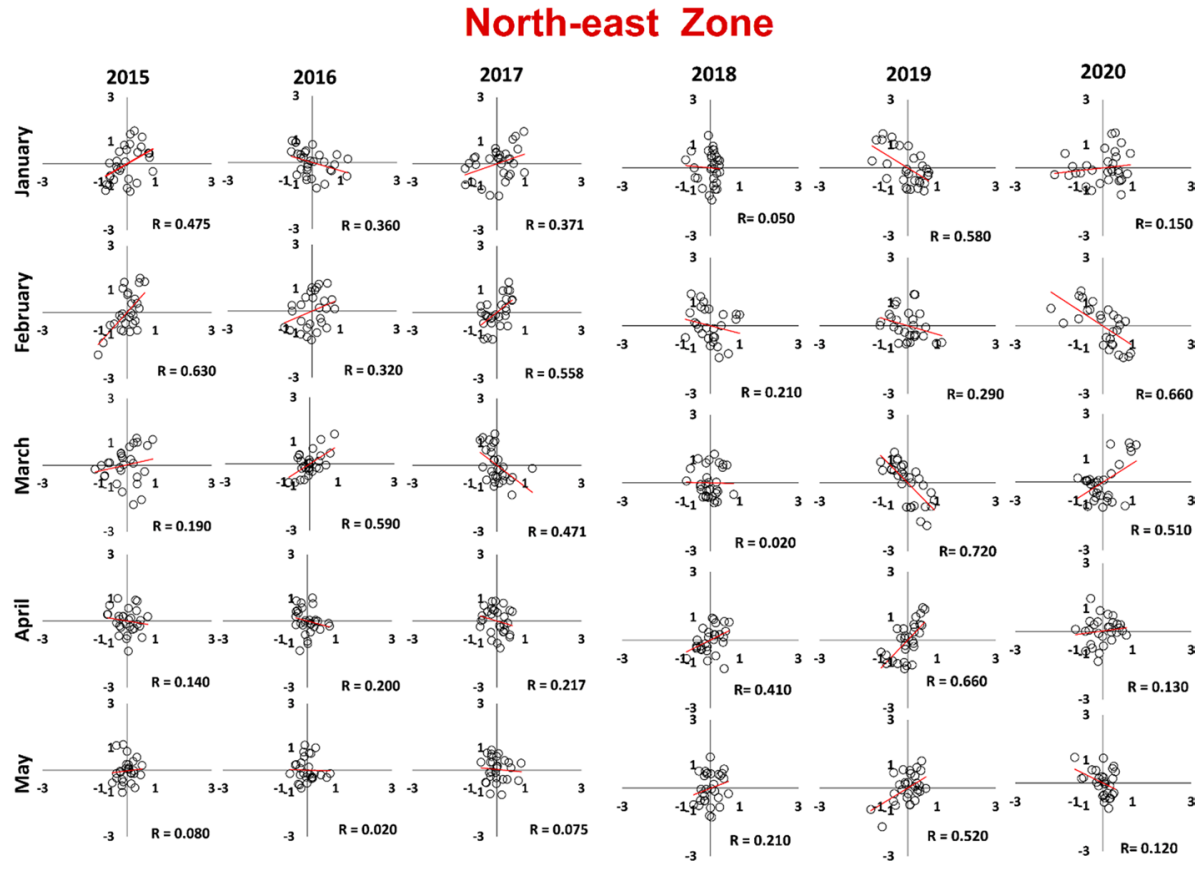

Fig. 14 Scatterplots showing the relation between monthly precipitation and temperature values in northeast zone for the years 2015, 2016, 2017, 2018, 2019 and 2020

\section{Central Zone}
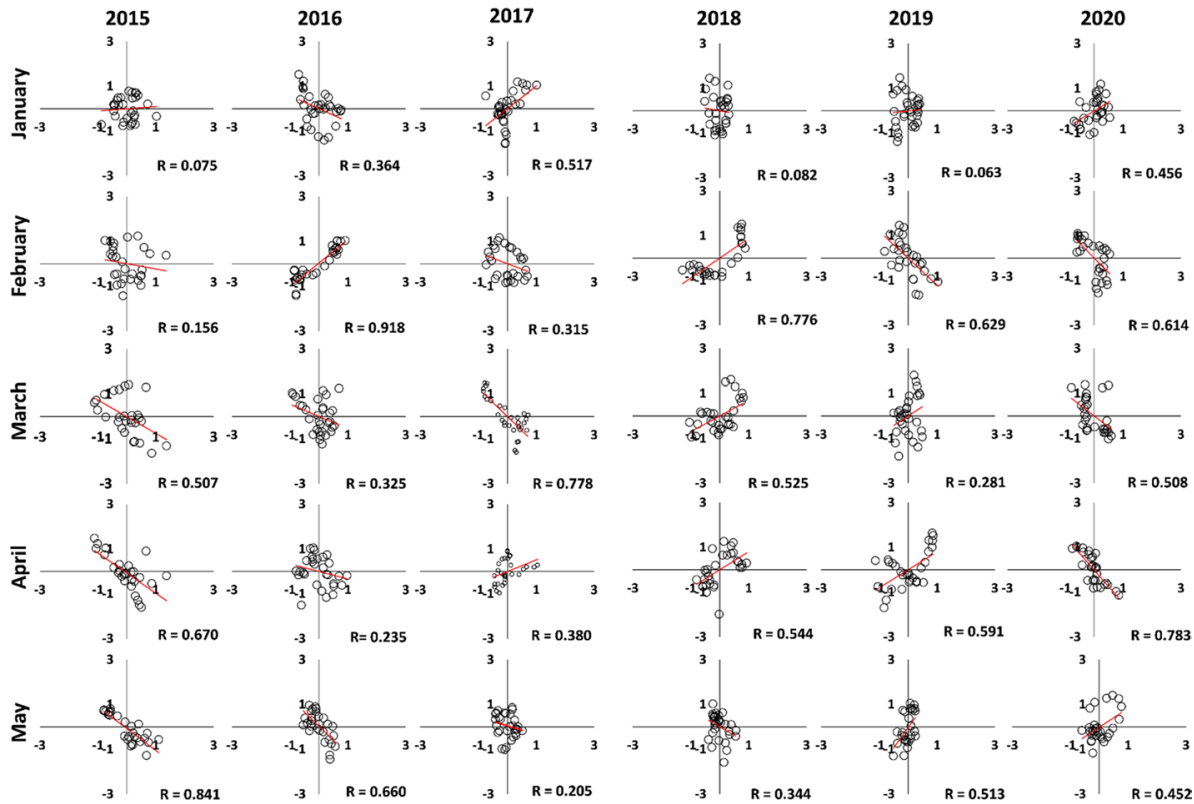

Fig. 15 Scatterplots showing the relation between monthly precipitation and temperature values in central zone for the years 2015, 2016, 2017, 2018, 2019, and 2020 
temperature and high rainfall, respectively. Studies of Macatsha (2005) revealed that temperature influences rainfall in several ways. In some situations, high temperature can lead to excessively high rates of potential evaporation and low precipitation, especially in an arid or semi-arid landscape region. As a large area of the NW and central zone lies in the arid or semi-arid region of the country, the finding of Macatsha (2005) can be corroborated with the outcomes of this study in terms of correlation (Fig. 16). The NE part of India is one of the most vulnerable areas, comprising Arunachal Pradesh, Assam, Manipur, Meghalaya, Mizoram, Nagaland, Tripura, West Bengal, Bihar, Jharkhand, and Chhattisgarh state with mostly composite climates. Most of the pixels of the NE zone were identified with a rising pattern of precipitation values along with values close to UWL, whereas some places were seen to have a lower precipitation value. The temperature of this zone was found to be in a rising pattern in most of the areas, while some of the pixels were seen to have a falling pattern. It is evident that years 2015, 2016, 2017 had a wide range of negative associations between the two climatic factors which might be the effect of more rainfall and less temperature which is analogous to the findings of Sharma et al. (2016). A small shift toward positively correlated values was observed in the year 2018 and was carried out in the succeeding year, especially in April and May. It was interesting to see a wide range of negative correlated values mainly because of the increased precipitation over temperature variation in the complete lockdown period. The zonal average temperature of the peninsular zone was identified with an inclination toward temperature increase from 2015 to 2019 but small shifts corresponding to the fall in temperature were detected in some pockets of this zone especially in the complete lockdown period, i.e., April and May (Fig. 17). If the 6-year monthly observed rainfall variability of this zone can be divided into two

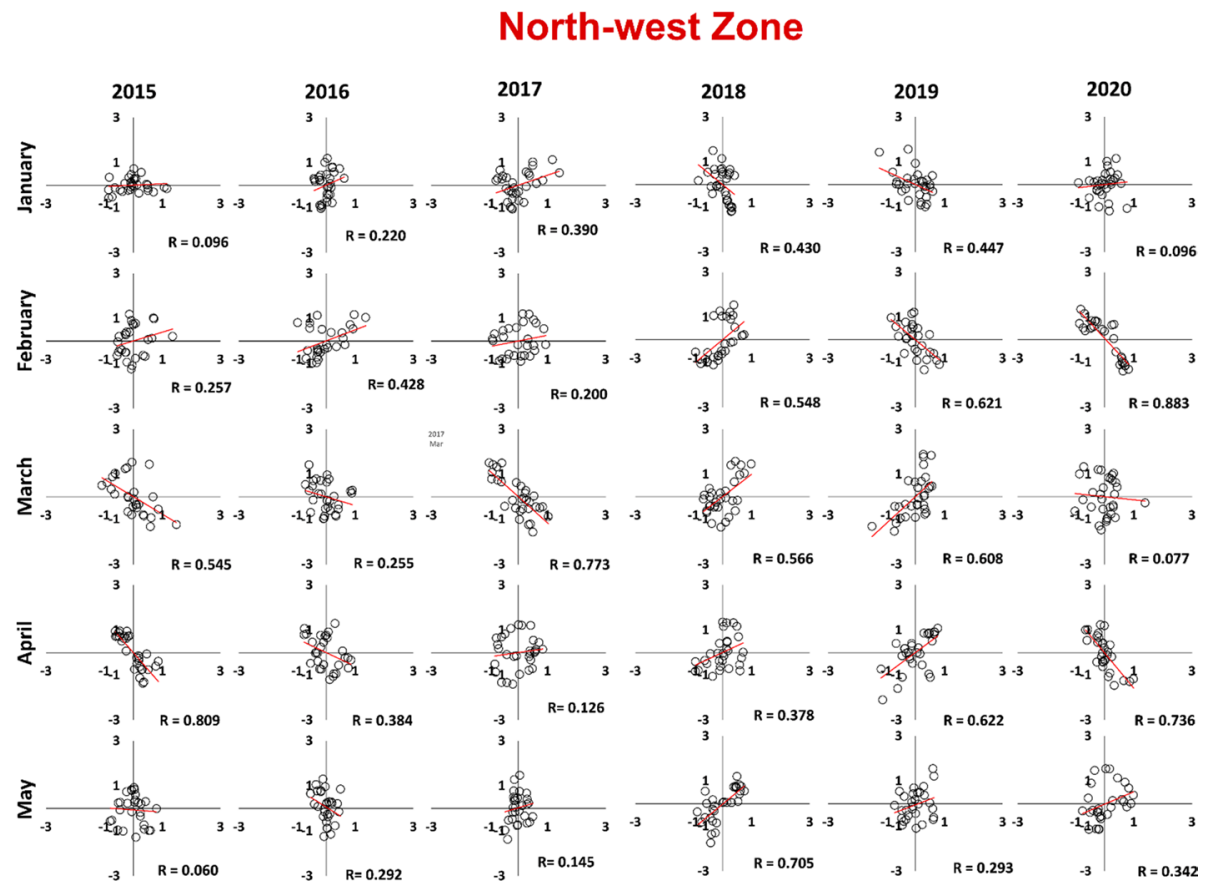

Fig. 16 Scatterplots showing the relation between monthly precipitation and temperature values in northwest zone for the years 2015, 2016, 2017, 2018, 2019, and 2020 


\section{Peninsular Zone}

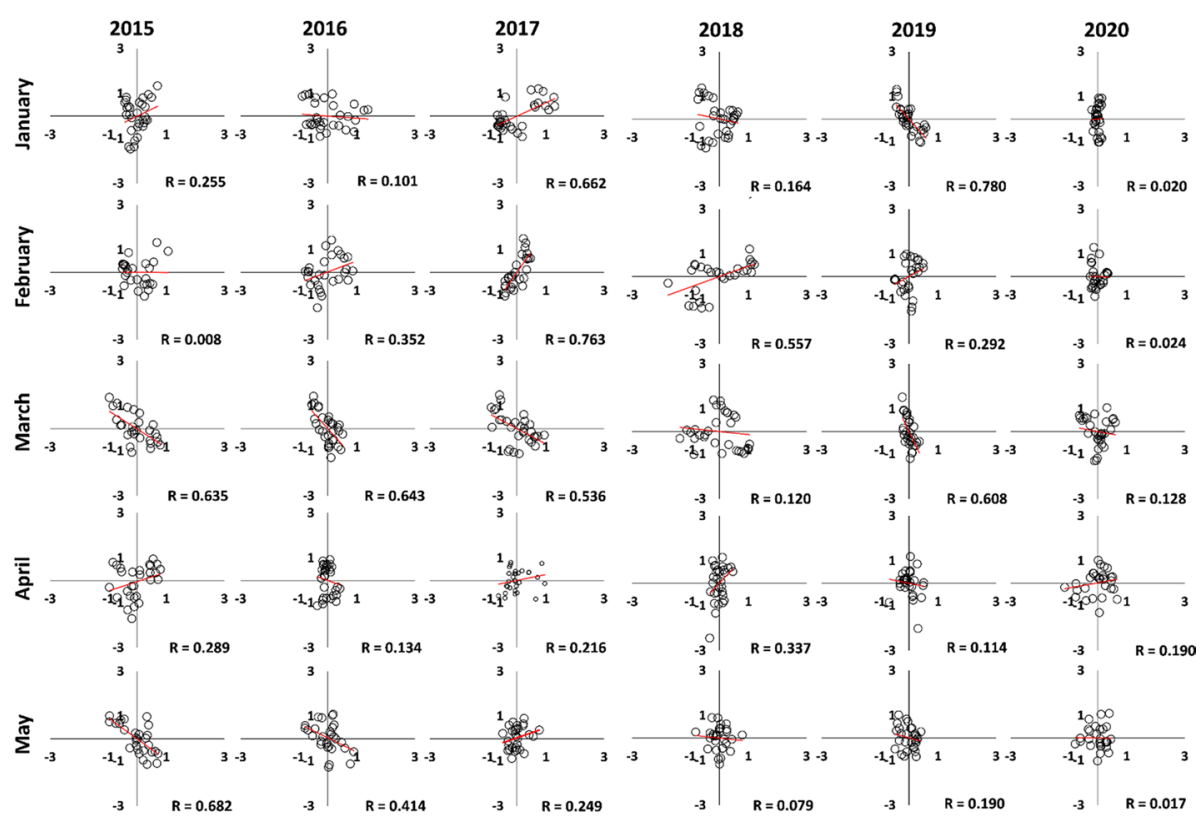

Fig. 17 Scatterplots showing the relation between monthly precipitation and temperature values in peninsular zone for the years 2015, 2016, 2017, 2018, 2019, and 2020

distinct times such as pre lockdown (January to middle of March) and post-lockdown (middle of March to May), a scarce rainfall can be seen in the pre-lockdown time in the entire 6-year time frame, whereas an increase in precipitation is clearly visible during the postlockdown period for the same time frame except for the year 2016. In the post-lockdown period, particularly in April and May for the year 2020, a significant increase in rainfall is highly evident in a vast region. Therefore, the maximum area of this zone was found to be in negative correlation (weak to moderate). Various studies (Bourke 1996; Zhao and Khalil 1993) related to the rainfall-temperature relationships revealed that the association between these two climatic variables is strong and weak, ranging from multi-decadal, interannual, monthly, and daily confirmed negative correlations. These studies for inter annual rainfall was conducted across different parts of Europe and Middle East with the result of positive correlation coefficient for daily data time series on different time scales. Nkuna and Odiyo (2016) used the Pearson correlation coefficient to establish a relation between temperature and precipitation (similar to the study) in the Levubu sub-catchment, South Africa, and found that the characteristics of the correlation values suggest that on a short time scale rainfall is influenced by temperature. This outcome of Nkuna and Odiyo (2016) is in harmony with the findings of this study. The mean monthly rainfall data from the correlation study showed upward trends in a few months and downward trends in other months for different years. However, we considered four climate zones for the analysis of the present research, but micro-level data such as various meteorological subdivision-wise data should be incorporated to be more accurate, so that high-precision development plan for micro-levels will then be achieved. 


\section{Conclusion}

This study is intended to identify the association between climatic parameters with reference to COVID-19 pandemic lockdown. The present study comprehensively studied precipitation and temperature data with the effect of complete nationwide lockdown in India. In the present study, 6 years (2015-2020) of daily temperature and rainfall data were analyzed. The zonal descriptive statistics were performed to measure the monthly zonal minimum, maximum, mean frequency distribution of the two climatic variables. The temperature and precipitation values were spatially plotted to perceive the zone-wise climatic changes. Further, for better analysis control charts (I-Chart and EWMA) were prepared to detect the small shifts. A spatial correlation study was performed to attempt an investigation for significant relationship between temperature and rainfall due to one of the COVID19 containment measures lockdown and inspect the extent of its variation. It was obvious mainly to find out if there were any falls in temperature and a rise in precipitation values. It was interesting to detect a weak to moderate negative correlation in many parts of the country in April 2020 after 2016. This study also identified a weak negative correlation mainly in NE zone in 2020 after 2017. The mean monthly rainfall data from the correlation study showed upward trends in a few months and downward trends in other months for different years. However, we considered four climate zones for the analysis of the present research, but micro-level data such as various meteorological subdivision-wise data should be incorporated to be more accurate, so that high-precision development plan for microlevels will then be achieved.

We agree the relatively short timeframe is a limitation of this analysis. Extending our study period up to ten years would have allowed differences to be identified more powerfully. Additional studies in other parts of India are highly desirable to reflect the scenario at the national level. Another limitation is that increases in standard deviations show that these increases in the pattern of precipitation are not constant, since higher standard variations imply a wider range of statistically predicted values. The results may be used in the future as a benchmark to begin a large-scale analysis of cohort studies across the country. Our study provides valuable knowledge that can enlighten local and national environmental decision-making authorities. As climate fluctuations are correlated with the SARS-CoV-2 lockdown, new strategies may be implemented to strengthen health systems or methods of social isolation, based on patterns of temperature and precipitation. This scientific study is crucial in guiding our meteorologists, hydrologists, planners, and other policymakers to update and amend future strategies to confront the burden of climatic incidents in India.

Funding This research did not receive any specific grant from funding agencies in the public, commercial, or not-for-profit sectors.

Availability of data and material No ethical approval was required. All the data are available in the public domain.

\section{Compliance with ethical standards}

Conflict of interest The authors declare that they have no conflict of interest. 


\section{References}

Allen, M. R., \& Ingram, W. J. (2002). Constraints on future changes in climate and the hydrologic cycle. Nature, 419(6903), 228-232. https://doi.org/10.1038/nature01092.

Ali, S., Sharma, M. R., \& Maiteya, V. K. (1993). Climatic classification for building design in India. Architectural Science Review, 36(1), 31-34. https://doi.org/10.1080/00038628.1993.9696730.

Anjum, N. A. (2020). Good in The Worst: COVID-19 Restrictions and Ease in Global Air Pollution. https://doi. org/10.20944/preprints202004.0069.v1

Arif, M., \& Sengupta, S. (2020). Nexus between population density and novel coronavirus (COVID-19) pandemic in the south Indian states: A geo-statistical approach. Environment, Development and Sustainability. https://doi.org/10.1007/s10668-020-01055-8.

Arora, S., Bhaukhandi, K. D., \& Mishra, P. K. (2020). Coronavirus lockdown helped the environment to bounce back. Science of the Total Environment, 140573, https://doi.org/10.1016/j.scitotenv.2020.140573.

Bakker, A., Kent, P., Derry, J., Noss, R., \& Hoyles, C. (2008). Statistical inference at work: Statistical process control as an example. Statistics Education Research Journal, 7(2), 130-145.

Bevan, J. M., \& Kendall, M. G. (1971). Rank correlation methods. The Statistician, 20(3), 74. https://doi. org/10.2307/2986801.

Bherwani, H., Nair, M., Musugu, K., Gautam, S., Gupta, A., Kapley, A., \& Kumar, R. (2020). Valuation of air pollution externalities: comparative assessment of economic damage and emission reduction under COVID-19 lockdown. Air Quality, Atmosphere \& Health, 13(6), 683-694. https://doi.org/10.1007/s1186 9-020-00845-3.

Bourke, P. (1996). Autocorrelation-2D Pattern Identification. Cross Correlation. Oxford University.

Berg, P., Haerter, J. O., Thejll, P., Piani, C., Hagemann, S., \& Christensen, J. H. (2009). Seasonal characteristics of the relationship between daily precipitation intensity and surface temperature. Journal of Geophysical Research, 114(D18). https://doi.org/10.1029/2009jd012008

Chatterjee, S., Khan, A., Akbari, H., \& Wang, Y. (2016). Monotonic trends in spatio-temporal distribution and concentration of monsoon precipitation (1901-2002), West Bengal, India. Atmospheric Research, 182, 54-75. https://doi.org/10.1016/j.atmosres.2016.07.010.

Census of India. (2011). Primary Census Abstract Highlights. https://censusindia.gov.in/2011-Common/Censu sData2011.html. (Accessed 6 June 2020).

Croarkin, C., Tobias, P., Filliben, J. J., Hembree, B., \& Guthrie, W. (2006). NIST/SEMATECH e-handbook of statistical methods. NIST/SEMATECH, July. http://www.itl.nist.gov/div898/handbook. .

Das, P. K., Midya, S. K., Das, D. K., Rao, G. S., \& Raj, U. (2017). Characterizing Indian meteorological moisture anomaly condition using long-term (1901-2013) gridded data: a multivariate moisture anomaly index approach. International Journal of Climatology, 38, e144-e159. https://doi.org/10.1002/joc.5359.

Deshpande, N. R., Kulkarni, A., \& Krishna Kumar, K. (2012). Characteristic features of hourly rainfall in India. International Journal of Climatology, 32(11), 1730-1744. https://doi.org/10.1002/joc.2375.

Dugam, S. S., \& Kakade, S. B. (2003). Indian monsoon variability in relation to regional pressure index. Journal of Earth System Science, 112(4), 521-527. https://doi.org/10.1007/bf02709777.

Environmental Systems Research Institute (ESRI). (2017). ArcGIS Release 10.2.1. Redlands, CA.

Eyvazian, M., Naini, S. J., \& Vaghefi, A. (2008). Monitoring process variability using exponentially weighted moving sample variance control charts. The International Journal of Advanced Manufacturing Technology, 39(3-4), 261-270. https://doi.org/10.1007/s00170-007-1213-7.

Gadgil., M., \& Guha, R. . (1993). This fissured land: an ecological history of India. Univ of California Press. https://doi.org/10.1093/acprof:oso/9780198077442.001.0001.

Gautam, S., \& Hens, L. (2020). SARS-CoV-2 pandemic in India: what might we expect? Environment, Development and Sustainability, 22(5), 3867-3869. https://doi.org/10.1007/s10668-020-00739-5.

Groisman, P. Y., Knight, R. W., Easterling, D. R., Karl, T. R., Hegerl, G. C., \& Razuvaev, V. N. (2005). Trends in intense precipitation in the climate record. Journal of Climate, 18(9), 1326-1350. https://doi.org/10.1175/ jcli3339.1.

Guhathakurta, P., \& Rajeevan, M. (2008). Trends in the rainfall pattern over India. International Journal of Climatology: A Journal of the Royal Meteorological Society, 28(11), 1453-1469. https://doi.org/10.1002/ joc. 1640 .

Guhathakurta, P., Rajeevan, M., Sikka, D. R., \& Tyagi, A. (2015). Observed changes in southwest monsoon rainfall over India during 1901-2011. International Journal of Climatology, 35(8), 1881-1898. https://doi. org/10.1002/joc.4095.

Haan, C. T. (1977). Statistical methods in hydrology. Iowa: The Iowa State University Press.

Huang, J., \& van den Dool, H. M. (1993). Monthly precipitation-temperature relations and temperature prediction over the United States. Journal of Climate, 6(6), 1111-1132. 
Huang, Y., Cai, J., Yin, H., \& Cai, M. (2009). Correlation of precipitation to temperature variation in the Huanghe River (Yellow River) basin during 1957-2006. Journal of Hydrology, 372(1-4), 1-8. https://doi. org/10.1016/j.jhydrol.2009.03.029.

Huq, S., Reid, H., Konate, M., Rahman, A., Sokona, Y., \& Crick, F. (2004). Mainstreaming adaptation to climate change in least developed countries (LDCs). Climate Policy, 4(1), 25-43. https://doi.org/10.3763/ cpol.2004.0404.

Ji, Y., Ma, Z., Peppelenbosch, M. P., \& Pan, Q. (2020). Potential association between COVID-19 mortality and health-care resource availability. The Lancet Global Health, 8(4), e480.

Joshi, U. R., \& Rajeevan, M. (2006). Trends in precipitation extremes over India. (Report No. 3/2006). National Climate Centre, India Meteorological Department. http://www.imdpune.gov.in/Clim_Pred_LRF_New/ Reports/NCCResearchReports/research_report_3.pdf

Justin, C., Tinashe, C. P., Jonas, Z. R., Jonathan, M., \& Marx, D. (2012). Application of statistical control charts to climate change detection in Masvingo City, Zimbabwe. Journal of Environmental Research and Development, 7(2), 780-786.

Kumar, K. R., Pant, G. B., Parthasarathy, B., \& Sontakke, N. A. (1992). Spatial and subseasonal patterns of the long-term trends of Indian summer monsoon rainfall. International Journal of climatology, 12(3), 257268. https://doi.org/10.1002/joc.3370120303.

Kumar, K. K., Kumar, K. R., \& Pant, G. B. (1997). Pre-monsoon maximum and minimum temperatures over India in relation to the summer monsoon rainfall. International Journal of Climatology: A Journal of the Royal Meteorological Society, 17(10), 1115-1127.

Lal, D. M., Ghude, S. D., Mahakur, M., Waghmare, R. T., Tiwari, S., Srivastava, M. K., et al. (2018). Relationship between aerosol and lightning over Indo-Gangetic Plain (IGP). India. Clim. Dyn., 50(9-10), 38653884. https://doi.org/10.1007/s00382-017-3851-2.

Laskar, S. I., Jaswal, K., Bhatnagar, M. K., \& Rathore, L. S. (2016). India Meteorological Department. Proceedings of the Indian National Science Academy, 82(3). 1021-1037. https://doi.org/10.16943/ptins $\mathrm{a} / 2016 / 48501$

Macatsha, N. (2005). Water Quality Monitoring in the SADC region. Published Master of Science in Engineering Thesis, University of Witwatersrand, South Africa.

Martinez-Austria, P. F., Bandala, E. R., \& Patiño-Gómez, C. (2016). Temperature and heat wave trends in northwest Mexico. Physics and Chemistry of the Earth, Parts A/B/C, 91, 20-26. https://doi.org/10.1016/j. pce.2015.07.005.

Naveed, M., Azam, M., Khan, N., \& Aslam, M. (2018). Design of a control chart using extended EWMA statistic. Technologies, 6(4), 108. https://doi.org/10.3390/technologies6040108.

Nkuna, T. R., \& Odiyo, J. O. (2016). The relationship between temperature and rainfall variability in the Levubu sub-catchment, South Africa. International Journal of Education and Learning Systems, 1.

Oakland, J. S. (2007). Statistical Process. Control. https://doi.org/10.4324/9780080551739.

Roy, M. P. (2020). Temperature and COVID-19: India. BMJ Evidence-Based Medicine. https://doi.org/10.1136/ bmjebm-2020-111459.

Pattanaik, D. R., \& Rajeevan, M. (2007). Northwest Pacific tropical cyclone activity and July rainfall over India. Meteorology and Atmospheric Physics, 95(1-2), 63-72. https://doi.org/10.1007/s00703-006-0193-0.

Perry, M. B. (2011). The Exponentially Weighted Moving Average. Wiley Encyclopedia of Operations Research and Management Science. https://doi.org/10.1002/9780470400531.eorms0314.

Rajeevan, M., Pai, D. S., \& Thapliyal, V. (1998). Spatial and temporal relationships between global land surface air temperature anomalies and Indian summer monsoon rainfall. Meteorology and Atmospheric Physics, 66(3-4), 157-171. https://doi.org/10.1007/bf01026631.

Rao, B. B., Chowdary, P. S., Sandeep, V. M., Rao, V. U. M., \& Venkateswarlu, B. (2014). Rising minimum temperature trends over India in recent decades: Implications for agricultural production. Global and Planetary Change, 117, 1-8. https://doi.org/10.1016/j.gloplacha.2014.03.001.

Sahai, A. K., Grimm, A. M., Satyan, V., \& Pant, G. B. (2003). Long-lead prediction of Indian summer monsoon rainfall from global SST evolution. Climate Dynamics, 20(7-8), 855-863. https://doi.org/10.1007/s0038 2-003-0306-8.

Schober, P., Boer, C., \& Schwarte, L. A. (2018). Correlation coefficients: appropriate use and interpretation. Anesthesia \& Analgesia, 126(5), 1763-1768. https://doi.org/10.1213/ane.0000000000002864.

Sonali, P., \& Kumar, D. N. (2013). Review of trend detection methods and their application to detect temperature changes in India. Journal of Hydrology, 476, 212-227.

SPC for Excel. (2013). Individuals Control Charts. https://www.spcforexcel.com/knowledge/variable-controlcharts/individuals-control-charts\#: :text=Individuals $\% 20$ control $\% 20$ charts $\% 20$ should $\% 20$ be, not $\% 20$ for \%20each\%20sample\%20taken. (Accessed 15 June 2020).

Six sigma study guide. (2015). EWMA Exponentially Weighted Moving Average Chart. https://sixsigmast udyguide.com/ewma-exponentially-weighted-moving-average-chart/ (Accessed 13 June 2020). 
Radhakrishnan, K., Sivaraman, I., Jena, S. K., Sarkar, S., \& Adhikari, S. (2017). A climate trend analysis of temperature and rainfall in India. Climate Change and Environmental Sustainability, 5(2), 146-153. https ://doi.org/10.5958/2320-642x.2017.00014.x.

Ratner, B. (2009). The correlation coefficient: Its values range between $+1 /-1$, or do they? Journal of Targeting, Measurement and Analysis for Marketing, 17(2), 139-142. https://doi.org/10.1057/jt.2009.5.

R Core Team. (2020). R: a language and environment for statistical computing. Vienna, Austria: R Foundation for Statistical Computing. Available at: https://www.r-project.org/. (Accessed 26th May 2020].

Şengöz, N. G. (2018). Control Charts to Enhance Quality. Quality Management Systems-a Selective Presentation of Case-Studies Showcasing Its Evolution, pp. 153-194. https://doi.org/10.5772/intechopen.73237

Sen, P. K. (1968). Estimates of the regression coefficient based on Kendall's tau. Journal of the American statistical association, 63(324), 1379-1389.

Schmid, W., \& Schöne, A. (1997). Some properties of the EWMA control chart in the presence of autocorrelation. The Annals of Statistics, 25(3), 1277-1283. https://doi.org/10.1214/aos/1069362748.

Sharma, C. S., Panda, S. N., Pradhan, R. P., Singh, A., \& Kawamura, A. (2016). Precipitation and temperature changes in eastern India by multiple trend detection methods. Atmospheric Research, 180, 211-225. https ://doi.org/10.1016/j.atmosres.2016.04.019.

Somani, M., Srivastava, A. N., Gummadivalli, S. K., \& Sharma, A. (2020). Indirect implications of COVID-19 towards sustainable environment: an investigation in Indian context. Bioresource Technology Reports, 11, 100491. https://doi.org/10.1016/j.biteb.2020.100491.

Stephenson, D. B., Diaz, H. F., \& Murnane, R. J. (2008). Definition, diagnosis, and origin of extreme weather and climate events. Climate extremes and society, 340, 11-23. https://doi.org/10.1017/CBO978051153584 0.004 .

The New York Times. (2020). India, Day 1: World's Largest Coronavirus Lockdown Begins. https://www.nytim es.com/2020/03/25/world/asia/india-lockdown-coronavirus.html. (Accessed 10 June 2020)

Trenberth, K. E., \& Shea, D. J. (2005). Relationships between precipitation and surface temperature. Geophysical Research Letters, 32(14), 129-142. https://doi.org/10.1029/2005g1022760.

Vucijak, B., Midzic Kurtagic, S., Ceric, A., Kupusovic, T., \& Spago, S. (2012). Assessment of Climate Change Effects to Precipitation Patterns using Statistical Process Control Methods. Annals of DAAAM, 277-280.

Utsumi, N., Seto, S., Kanae, S., Maeda, E. E., \& Oki, T. (2011). Does higher surface temperature intensify extreme precipitation?. Geophysical Research Letters, 38(16). https://doi.org/10.1029/2011g1048426

Valdiya, K. S. (2016). Physiographic layout of Indian subcontinent. In The Making of India (pp. 1-19). Springer, Cham. https://doi.org/10.1007/978-3-319-25029-8_1

WHO. (2020a). Coronavirus Disease (COVID-2019) India Situation Report - 1. https://www.who.int/docs/ default-source/wrindia/india-situation-report-1.pdf?sfvrsn=5ca2a672_0. (Accessed 31 April 2020).

WHO. (2020b). WHO director-General's opening remarks at the media briefing on COVID19-11 march 2020. https://www.who.int/dg/speeches/detail/who-director-general-s-opening-remarks-at-the-media-briefingon-covid-19---11-march-2020. (Accessed 10 May 2020).

Zhao, W., \& Khalil, M. A. K. (1993). The relationship between precipitation and temperature over the contiguous United States. Journal of climate, 6(6), 1232-1236.

Zheng, Y., Bourassa, M. A., Ali, M. M., \& Krishnamurti, T. N. (2016). Distinctive features of rainfall over the Indian homogeneous rainfall regions between strong and weak Indian summer monsoons. Journal of Geophysical Research: Atmospheres, 121(10), 5631-5647. https://doi.org/10.1002/2016jd025135.

Zu, Z. Y., Jiang, M. D., Xu, P. P., Chen, W., Ni, Q. Q., Lu, G. M., \& Zhang, L. J. (2020). Coronavirus disease 2019 (COVID-19): a perspective from China. Radiology, 200490, . https://doi.org/10.1148/radiol.20202 00490.

Publisher's Note Springer Nature remains neutral with regard to jurisdictional claims in published maps and institutional affiliations.

\section{Authors and Affiliations}

\section{Soumita Sengupta ${ }^{1}$ (D) $\cdot$ Sk. Mohinuddin ${ }^{1} \cdot{\text { Mohammad } \text { Arif }^{2} \text { [D }}^{-}$}

Mohammad Arif

arifaligs@yahoo.com

1 Department of Remote Sensing, Birla Institute of Technology, Mesra, Jharkhand 835215, India

2 Department of Geography, Central University of Jharkhand, Ranchi, Jharkhand 835222, India 